\title{
A Signaling Cascade of Nuclear Calcium-CREB-ATF3 Activated by Synaptic NMDA Receptors Defines a Gene Repression Module That Protects against Extrasynaptic NMDA Receptor-Induced Neuronal Cell Death and Ischemic Brain Damage
}

\author{
Sheng-Jia Zhang, ${ }^{1}$ Bettina Buchthal, ${ }^{1}$ David Lau, ${ }^{1}$ Stefanie Hayer, ${ }^{1}$ Oliver Dick, ${ }^{1}$ Markus Schwaninger, ${ }^{2}$ \\ Roland Veltkamp, ${ }^{3}$ Ming Zou, ${ }^{1}$ Ursula Weiss, ${ }^{1}$ and Hilmar Bading ${ }^{1}$ \\ ${ }^{1}$ Department of Neurobiology and Interdisciplinary Center for Neurosciences and Departments of ${ }^{2}$ Pharmacology and ${ }^{3}$ Neurology, University of \\ Heidelberg, 69120 Heidelberg, Germany
}

Synapse-to-nucleus signaling triggered by synaptic NMDA receptors can lead to the buildup of a neuroprotective shield. Nuclear calcium activating the cAMP response element binding protein (CREB) plays a key role in neuroprotection acquired by synaptic activity. Here we show that in mouse hippocampal neurons, the transcription factor Atf3 (activating transcription factor 3 ) is a direct target of CREB. Induction of ATF3 expression by CREB in hippocampal neurons was initiated by calcium entry through synaptic NMDA receptors and required nuclear calcium transients and calcium/calmodulin-dependent protein kinase IV activity. Acting as a transcriptional repressor, ATF3 protects cultured hippocampal neurons from apoptosis and extrasynaptic NMDA receptor-induced cell death triggered by bath application of NMDA or oxygen-glucose deprivation. Expression of ATF3 in vivo using stereotaxic delivery of recombinant adenoassociated virus reduces brain damage following a cerebral ischemic insult in mice. Conversion of ATF3 to a transcriptional activator transforms ATF3 into a potent prodeath protein that kills neurons in cell culture and, when expressed in vivo in the hippocampus, ablates the neuronal cell layer. These results link nuclear calcium-CREB signaling to an ATF3-mediated neuroprotective gene repression program, indicating that activity-dependent shutoff of genes is an important process for survival. ATF3 supplementation may counteract age- and disease-related neuronal cell loss caused by a reduction in synaptic activity, malfunctioning of calcium signaling toward and within the nucleus ("nuclear calciopathy"), or increases in death signaling by extrasynaptic NMDA receptors.

\section{Introduction}

The well-being of neurons in the mammalian CNS is dependent on the balance of the activities of the survival-promoting synaptic NMDA receptor and the extrasynaptic NMDA receptor that in-

Received May 25, 2010; revised Jan. 4, 2011; accepted Jan. 11, 2011.

This work was supported by the Alexander von Humboldt Foundation (Wolfgang-Paul-Prize to H.B.), the European Research Council Advanced Grant (H.B.), the Deutsche Forschungsgemeinschaft (DFG) Graduate College 791 (D.L.), the DFG, Sonderforschungsbereich (SFB) 488 and SFB636 of the DFG, Graduate Academy (Excellence Initiative) of Heidelberg University, the European Union (EU) Network of Excellence NeuroNE, and the EU Project GRIPANNT (Glutamate Receptor Interacting Proteins as Novel Neuroprotective Targets). H.B. and M.S. are members of the Excellence Cluster CellNetworks at Heidelberg University. We thank Iris Bünzli-Ehret for her help with the preparation of hippocampal cultures, Christian Ackermann and Ulrike Engel for help with the time lapse video microscopy, and $\mathrm{H}$. Eckehard Freitag for the construction of synapsin I promoter-containing rAAV-expressing VP16-ATF3 and EGFP. We thank Drs. John Dedman, Eric Olson, Eric Kandel, Tsonwin Hai, Donald Steiner, David Ginty, and Anthony Means for supplying plasmids.

Correspondence should be addressed to Hilmar Bading, Department of Neurobiology, Interdisciplinary Centre for Neurosciences, University of Heidelberg, Im Neuenheimer Feld 364, 69120 Heidelberg, Germany. E-mail: Hilmar.Bading@uni-hd.de.

S.-J. Zhang's present address: Kavli Institute for Systems Neuroscience, Centre for the Biology of Memory, Norwegian University of Science and Technology, 7489 Trondheim, Norway.

M. Zou's present address: Friedrich Miescher Institute for Biomedical Research, 4058 Basel, Switzerland.

DOI:10.1523/JNEUROSCI.2672-10.2011

Copyright $\odot 2011$ the authors $\quad 0270-6474 / 11 / 314978-13 \$ 15.00 / 0$ duces cell death pathways (Hardingham et al., 2002; Hardingham and Bading, 2010). Important for the acquisition of a long-lasting neuroprotective shield following calcium entry through synaptic NMDA receptors is the propagation of calcium signals into the nucleus, the subsequent formation of a nuclear calcium/calmodulin complex, and the initiation of a genomic response (Bading, 2000, Hardingham et al., 2001; 2002; Lee et al., 2005; Papadia et al., 2005; Zhang et al., 2007; 2009; Bengtson et al., 2010). Nuclear calcium is one of the most potent activators of neuronal gene expression and controls a large gene pool that includes a gene program for acquired neuroprotection (Zhang et al., 2009). The transcription factor cAMP response element binding protein (CREB), a key target of nuclear calcium signaling (Hardingham et al., 1997; 2001; Chawla et al., 1998; Zhang et al., 2009), plays an important role in neuronal survival (Mantamadiotis et al., 2002). However, CREB is a multifunctional transcriptional regulator (Mayr and Montminy, 2001; Carlezon et al., 2005) that is also involved in a number of other processes including neuronal plasticity, addiction, neurogenesis, learning, and memory (Carlezon et al., 1998; Silva et al., 1998; Lonze and Ginty, 2002; Zhu et al., 2004; Giachino et al., 2005). CREB signaling may control multi- 
ple processes through the activation of target genes, which themselves may encode transcription factors and regulate functionspecific genomic subroutines. The concept of a hierarchical transcription factor cascade that starts with a master regulator and branches off to other DNA binding proteins that serve a specific function is not new and has been implemented to control biological processes such as the specification of the body plan and pattern formation in embryonic development (Anderson, 1999; Pearson et al., 2005; Peel et al., 2005; Dequéant and Pourquié, 2008). In this study, we show that the transcriptional repressor ATF3 acts downstream of CREB to mediate the survival function. ATF3 is a direct CREB target that can protect neurons both in vitro and in vivo from death induced by stimulation of extrasynaptic NMDA receptors. CREB-ATF3 signaling, which is controlled by synaptic NMDA receptors and nuclear calcium, represents the core of an activity-regulated survival module that involves the sequential activation of transcriptional induction and gene repression.

\section{Materials and Methods}

Hippocampal cultures and stimulations. Hippocampal neurons from newborn C57/Black6 mice were cultured in Neurobasal medium (Invitrogen) containing 1\% rat serum, B27 (Invitrogen), and penicillin and streptomycin (Sigma). The procedure used to isolate and culture hippocampal neurons has been described (Bading and Greenberg, 1991; Bading et al., 1993; Zhang et al., 2007). Stimulations were done after a culturing period of 9-12 d, during which hippocampal neurons develop a rich network of processes, express functional NMDA-type and AMPA/ kainate-type glutamate receptors, and form synaptic contacts (Bading et al., 1995; Hardingham et al., 2001). Action potential bursting was induced by treatment with the $\mathrm{GABA}_{\mathrm{A}}$ receptor antagonist bicuculline $(50 \mu \mathrm{M})$ as described previously (Hardingham et al., 2001, 2002; Arnold et al., 2005). In the survival experiments, neurons were treated for $16 \mathrm{~h}$ with bicuculline in the presence of $250 \mu \mathrm{M} 4$-amino pyridine (4-AP) (Hardingham et al., 2002). 4-AP increases the frequency of the bicuculline-induced action potential bursts, thereby enhancing nuclear calcium, CREB-mediated transcription, and activity-induced neuroprotection (Hardingham et al., 2001, 2002; Arnold et al., 2005). D(-)-2-Amino-5phosphonopentanoic acid and MK-801 were from Sigma, tetrodotoxin (TTX) was from Tocris Bioscience, 4-AP and staurosporine were from Calbiochem, and the caspase inhibitor $N$-benzyloxycarbonyl-Val-Ala$\operatorname{Asp}(\mathrm{O}-\mathrm{Me})$ fluoromethyl ketone (Z-VAD-FMK) was from Promega.

Reporter gene analysis. The cDNAs for DsRed (Clontech) and ATF3 were cloned into pCMV-BD (Stratagene) to generate pCMV-Gal4-dsRed and pCMV-Gal4-Atf3. pBD-NF-kB (Stratagene) containing the Gal4 DNA binding domain fused to the transcription activation domain of NF- $\kappa \mathrm{B}$ was used as positive control. The luciferase (luc) reporter gene pGL2-5 $\times$ Gal4-TK-luc reporter (Fujita et al., 2004) was provided by P.A. Wade (Emory University, Atlanta, GA). For the Gal4-based reporter assays, hippocampal neurons were cotransfected using Lipofectamine 2000 (Invitrogen) with pGL2-5×Gal4-TK-luc, the expression vectors for Gal4 fusion proteins, and the pAAV-hRluc as reference plasmid for normalization of transfection efficiency using a ratio of $8: 1: 1$. To generate pAAV-hRluc (Lau and Bading, 2009), the cDNA for humanized renilla luciferase (from pGL4.70, Promega) was cloned into a cytomegalovirus (CMV)/chicken $\beta$-actin hybrid promoter-driven adeno-associated viral expression plasmid. Details of AAV plasmid backbone have been described (Klugmann et al., 2005). The cells were harvested $48 \mathrm{~h}$ posttransfection.

For the Atf3-promoter study, an 81-bp-long fragment of the mouse Atf3 proximal promoter region that contains a cAMP response element (CRE) and a binding site for MEF2 (monocyte enhancer factor 2) termed the MEF2 response element (MRE) was inserted into the NheI/BglII sites of pGL4.10 (Promega) to generate Atf3-wt-luc. Three variants of this wild-type (wt) Atf3 promoter construct were generated that contain a mutation in either the CRE (Atf3- $\Delta$ CRE-luc) or the MRE (Atf3- $\triangle$ MREluc) or in both the CRE and the MRE (Atf3- $\Delta$ MRE $\Delta$ CRE-luc). The fol- lowing oligonucleotides were used for reporter gene construction; the CRE and the MRE are in bold letters, and mutations are underlined:

Atf3-wt-luc: GCTAGCAGCTATTAATAGCATTACGTCAGCCTGGGATTGGTAACCTGGAGTTAAGCGGGCTCCCTGCCAACGCGAGGGCTTTAAAAGAGATCT.

Atf3- $\triangle$ MRE-luc: GCTAGCAGCTATTGCGAGCATTACGTCAGCCTGGGATTGGTAACCTGGAGTTAAGCGGGCTCCCTGCCAACGCGAGGGCTTTAAAAGAGATCT.

Atf3- $\triangle$ CRE-luc: GCTAGCAGCTATTAATAGCATTTGGTCAGCCTGGGATTGGTAACCTGGAGTTAAGCGGGCTCCCTGCCAACGCGAGGGCTTTAAAAGAGATCT.

Atf3- $\Delta$ MRE $\Delta$ CRE-luc: GCTAGCAGCTATTGCGAGCATTTGGTCAGCCTGGGATTGGTAACCTGGAGTTAAGCGGGCTCCCTGCCAACGCGAGGGCTTTAAAAGAGATCT.

The reporter plasmids were cotransfected at a ratio of 8:1 together with pGL4.70 containing a basic expression cassette for the humanized renilla luciferase (hRluc). Neurons were stimulated $24 \mathrm{~h}$ posttransfection to induce action potential bursting for $48 \mathrm{~h}$ using $50 \mu \mathrm{M} \mathrm{Bic} / 250 \mu \mathrm{M} 4-\mathrm{AP}$ (Hardingham et al., 2001) and harvested. Luciferase activities in extracts from hippocampal neurons were measured with the Dual-Luciferase Assay Kit (Promega) and the Glomax Microplate Luminometer (Turner Biosystems). Data represent mean values $( \pm$ SEM) from at least three independent experiments, each performed in duplicate.

Time lapse video microscopy. For time lapse video microscopy, hippocampal neurons were transfected with a rAAV plasmid harboring two synapsin I promoter-containing expression cassettes for VP16-ATF3 and enhanced green fluorescent protein (EGFP), respectively (H. E. Freitag and $\mathrm{H}$. Bading, unpublished observations). The EGFP fluorescence was monitored using a Nikon BioStation IM automated life cell incubation and imaging system (Nikon Instruments) at the Nikon Imaging Center, University of Heidelberg, Heidelberg, Germany. Pictures were taken every $10 \mathrm{~min}$ over a period of $\sim 57 \mathrm{~h}$.

Antibodies. Antibodies to the following proteins were used: ATF3 (rabbit polyclonal antibody; Santa Cruz Biotechnology); CREB (rabbit monoclonal antibody; Cell Signaling Technology); MEF2C (rabbit polyclonal antibody; Cell Signaling Technology); Flag (ANTI-FLAG M2 mouse monoclonal antibody; Sigma); calmodulin (mouse monoclonal antibody; Millipore); humanized Renilla reniformis green fluorescent protein (hrGFP) (rabbit polyclonal antibody; Stratagene); hemagglutinin (HA) tag (rabbit polyclonal antibody; Santa Cruz Biotechnology). Immunoblot and immunocytochemistry were done according to standard procedures.

Recombinant adeno-associated virus and viral infections. The vectors used to construct and package recombinant adeno-associated viruses (rAAVs) have been described previously (Klugmann et al., 2005; Zhang et al., 2007; 2009). The following CMV/chicken $\beta$-actin hybrid promoter-driven rAAV expression plasmids were generated by standard molecular biology techniques and confirmed by DNA sequencing: rAAV-Atf3, rAAV-CaMBP4, rAAV-A-CREB, rAAV-CaMKIV(K75E), rAAV-CaMKIV(1-313), rAAV-VP16-Atf3, rAAV-VP16-CREB, rAAVVP16-MEF2C, and rAAV-hrGFP. The synapsin I promoter-containing rAAV expressing both VP16-ATF3 and EGFP was generated by H. Eckehard Freitag, University of Heidelberg, Heidelberg, Germany (H. E. Freitag and $\mathrm{H}$. Bading, unpublished observations). cDNA clones that served as templates for PCR-based cloning of the different rAAV constructs were provided by Drs. Eric Olson (University of Texas Southwestern, Dallas, TX), Eric Kandel (Columbia University, New York, NY), Anthony Means (Duke University, Durham, NC), David Ginty (Johns Hopkins University, Baltimore, MD), John Dedman (University of Cincinnati, Cincinnati, OH), and Donald Steiner (University of Chicago, Chicago, IL) or originate from phrGFP-1 (Stratagene) in the case of the cDNA for hrGFP expression. rAAV-expressed proteins carry a Flag tag except for $h r G F P$. Hippocampal neurons were infected with recombinant rAAVs at $4 \mathrm{~d}$ in vitro (DIV). Infection efficiencies were routinely determined immunocytochemically at 9 or 10 DIV by using antibodies to the Flag tag, HA tag, or hrGFP or by analyzing the fluorescence of hrGFP; they ranged from 80 to $95 \%$ of the viable neurons. The use of rAAV- $A$ $C R E B$ is complicated by the observation that high levels of A-CREB expression in hippocampal neurons can compromise the health of the 
cells. In the design of the experiments with rAAV-A-CREB, care was taken to minimize A-CREB-induced cell death; the amount of rAAV-A$C R E B$ was titrated and the minimum amount of virus needed to obtain an infection rate of $\sim 80-85 \%$ was used.

Chromatin immunoprecipitation. Cultured mouse hippocampal neurons $\left(1-2 \times 10^{6}\right.$ cells $)$ were processed for chromatin immunoprecipitation (ChIP) assays at 10 DIV. For chromatin cross-linking, formaldehyde (Sigma) was added to the medium to a final concentration of $1 \%(\mathrm{v} / \mathrm{v})$ followed by incubation at room temperature for $15 \mathrm{~min}$ on a rocking platform. The cross-linking reaction was stopped by the addition of glycine to a final concentration of $0.125 \mathrm{~m}$ followed by a $5 \mathrm{~min}$ incubation at room temperature with gentle swirling. After two brief washes with cold PBS containing a protease inhibitor cocktail (Roche), the cross-linked neurons were scraped off the dish with a cell scraper, transferred into an Eppendorf tube, and spun down at $2000 \times g$ for $10 \mathrm{~min}$. The cell pellet was resuspended in 200 $\mu l$ of SDS lysis buffer (1\% SDS, 10 mm EDTA, 50 mm Tris, $\mathrm{pH}$ 8.1) and placed on ice for $10 \mathrm{~min}$. The resulting extract was sonicated using Branson microtip sonicator model D- 450 with 4 pulses of $5 \mathrm{~s}$ each at a power setting of $40 \%$. Between each pulse, the extract was incubated in an ice-water bath for $2 \mathrm{~min}$. After this step, the processing of all experimental samples and total input was carried out with the ChIP kit (Millipore). For the immunoprecipitation, either $10 \mu \mathrm{g}$ of antibodies to CREB or MEF2C or $10 \mu \mathrm{g}$ of normal rabbit IgG (Sigma) was added to the precleared sample, which was incubated at $4^{\circ} \mathrm{C}$ with rotation for $16 \mathrm{~h}$. The recovered immunoprecipitated DNA or input DNA was resuspended in $120 \mu \mathrm{l}$ of $\mathrm{H}_{2} \mathrm{O}$, of which $2 \mu \mathrm{l}$ were used for detecting the presence of the target gene promoter sequences with PCR by using HotStarTaq Master Mix Kit (Qiagen). Input DNA and immunoprecipitated chromatin were analyzed first in pilot experiments to ensure that PCRs were occurring in the linear range of amplification. The primers used for PCR were as follows: Atf3 promoter (sense): 5'-CGTCAGCCTGGGATTGGTAA-3', Atf3 promoter (antisense): $5^{\prime}$-GTTGCATCACCCCTTTTAAAGC-3'; $c$-fos promoter (sense): 5'-AGATGTATGCCAAGACGGGGG-3' ${ }^{\prime}, c$-fos promoter (antisense): $5^{\prime}$-CAGTCGCGGTTGGAGTAGTAG-3'; Nur77 promoter (sense): 5'-CCTAGTGGGTCTGGAAGCTA-3', Nur77 promoter (antisense): 5'-AGCGCGGATTGTTTGATC-3'; Nucleolin promoter (sense): 5'-CCCTCGTCAAGCCTTA-3', Nucleolin promoter (antisense): 5'-AGTAATCGCCTCTGGAAA-3'.

Quantitative reverse transcriptase PCR. To determine the mRNA expression levels of Atf3, c-fos, and glyceraldehyde-3-phosphate dehydrogenase (Gapdh), quantitative reverse transcription PCR (QRT-PCR) was performed using real-time TaqMan technology with a sequence detection system model 7300 real-time PCR system (Applied Biosystems). Total RNA was extracted using RNeasy Mini Kit (Qiagen) with additional on-column DNase digestion during RNA purification. For the generation of the first strand cDNA, 3-5 $\mu \mathrm{g}$ of total RNA was reverse transcribed by extension of oligo $(\mathrm{dT})_{20}$ primers using SuperScript III reverse transcriptase (Invitrogen) according to the manufacturer's instructions. QRT-PCR was performed using TaqMan Universal PCR Master Mix (Applied Biosystems) with Assays-on Demand Gene Expression Products, which are ready to use primers and probe sets designed by Applied Biosystems. The mouse Atf3-, c-fos-, and Gapdh-specific probes were Assays-on-Demand Gene Expression Products with TaqMan MGB probes, FAM dye labeled (assay identifiers Mm00476032 for Atf3, Mm00487425 for $c$-fos, and Mm99999915 for Gapdh). The thermal cycling conditions comprised $10 \mathrm{~min}$ at $95^{\circ} \mathrm{C}, 45$ cycles of $15 \mathrm{~s}$ for denaturation at $95^{\circ} \mathrm{C}$, and $60 \mathrm{~s}$ for annealing and extension at $60^{\circ} \mathrm{C}$. The expression levels of the target mRNA was normalized to the relative ratio of the expression of Gapdh mRNA using the $\Delta \Delta \mathrm{Ct}$ cycle threshold method. Each QRT-PCR assay was performed at least three times, and the results are expressed as the means \pm SEM. Similar gene expression results were obtained in gene expression studies using cDNA synthesized with random primers, and $18 S$ rRNA as well as gusb as reference genes (data not shown).

Assessment of neuroprotective activity in vitro. As described previously (Hardingham et al., 2002; Papadia et al., 2005; Zhang et al., 2007), two types of assays were used to investigate apoptotic cell death and the protection from cell death afforded by a period of action potential bursting. At $10 \mathrm{DIV}$, activity-dependent survival was induced by treatment of the neurons for $16 \mathrm{~h}$ with bicuculline $(50 \mu \mathrm{M})$ and 4 -AP $(250 \mu \mathrm{M})$. All electrical activity of the network was subsequently stopped using TTX (1 $\mu \mathrm{M})$ followed by keeping the cells in either regular medium (containing growth and trophic factors) with or without staurosporine (10 nM) or in medium lacking growth and trophic factors, all in the presence of TTX (1 $\mu \mathrm{M})$. The principal growth and trophic factors in the regular serum-free hippocampal medium [termed transfection medium (TM)] (Bading et al., 1993) are insulin, transferrin, and selenium. Staurosporine-induced apoptosis and growth factor withdrawal-induced apoptosis were assessed after 36 and $72 \mathrm{~h}$, respectively, by determining the percentage of hippocampal neurons with shrunken cell body and large round chromatin clumps characteristic of apoptotic death (Hardingham et al., 2002; Papadia et al., 2005; Zhang et al., 2007, 2009). In the growth factor withdrawal assays, basal cell death is slightly higher because of the differences in the time that the neurons are kept in serum free, TTX-containing media. At least 20 visual fields from each coverslip (corresponding to $1500-2000$ cells per coverslip) were counted. For oxygen-glucose deprivation (OGD), hippocampal neurons at 10 DIV were washed three times with deoxygenated glucose-free salt solution containing (in mM) 140.1 $\mathrm{NaCl}, 5.3 \mathrm{KCl}, 1.0 \mathrm{MgCl}_{2}, 2.0 \mathrm{CaCl}_{2}, 10.0$ HEPES, pH 7.4, 1.0 glycine, and 0.5 sodium pyruvate and then transferred to an anaerobic chamber containing a $5 \% \mathrm{CO}_{2}$ and $95 \% \mathrm{~N}_{2}$ atmosphere. Control cultures were kept for the same time in oxygenated TM in a normal atmosphere. After 1, 2, or $3 \mathrm{~h}$ at $37^{\circ} \mathrm{C}$, OGD was terminated by adding oxygenated TM to the neurons. The cultures were maintained for an additional period of $24-$ $27 \mathrm{~h}$ at $37^{\circ} \mathrm{C}$ in a humidified atmosphere containing $5 \% \mathrm{CO}_{2}$ and $95 \%$ air before incubating for $10 \mathrm{~min}$ in propidium iodide (PI; $2 \mu \mathrm{g} / \mathrm{ml}$ ) in TM. Neurons were washed three times with TM, fixed with $4 \%$ paraformaldehyde in PBS, and counterstained with Hoechst 33258. For each dye, 5 images were taken at a $10 \times$ magnification with a spot camera mounted on a Leica DMRB microscope. The images were binarized and nuclei were counted automatically using the ImageJ software. The percentage of dead cells was calculated as the ratio of dead (i.e., PI-positive) and all (i.e., Hoechst-positive) cells. For NMDA-induced cell death, hippocampal neurons at 10 DIV were exposed for $10 \mathrm{~min}$ to $20 \mu \mathrm{M}$ NMDA in TM. After an additional period of $6 \mathrm{~h}$, neurons were fixed, stained with Hoechst 33258 , and the percentage of dead cells was determined. The TUNEL-In Situ Cell Death Detection Kit (Roche) was used according to the manufacturer's instructions (where TUNEL is terminal deoxynucleotidyl transferase-mediated biotinylated UTP nick end labeling). All cell death analyses were done without knowledge of the treatment history of the cultures. All results are given as means \pm SEM; statistical significance was determined by ANOVA or Student's $t$ test.

Stereotaxic injections and assessment of VP16-ATF3-induced cell death in slices. rAAVs (rAAV-Atf3, rAAV-mCherry, rAAV-hrGFP, rAAVVP16-Atf3, and rAAV empty vector control) were delivered by stereotaxic injection into the dorsal hippocampus of male Sprague Dawley rats weighing $230-250 \mathrm{~g}$ or into the cerebral cortex of young adult male C57/Black6 mice (Charles River Laboratories) weighing $25 \pm 1$ g. Rats were randomly grouped and anesthetized with ketamine. A total volume of $3 \mu \mathrm{l}$ containing $3 \times 10^{8}$ genomic virus particles was injected unilaterally over a period of $30 \mathrm{~min}$ at the following coordinates relative to bregma: anteroposterior (AP), $-3.8 \mathrm{~mm}$; mediolateral (ML), $2.8 \mathrm{~mm}$; dorsoventral (DV), -2.8 to $-3.8 \mathrm{~mm}$ from the skull surface. Mice were randomly grouped and anesthetized with a mixture of medetomidin, midazolam, and fentanyl. A total volume of $2.0 \mu$ l containing $1-2 \times 10^{9}$ genomic virus particles were injected into the left cortex with a speed of $200 \mathrm{nl} / \mathrm{min}$ at the following coordinates relative to bregma: first site: AP, $0.2 \mathrm{~mm}$; ML, 2.0; DV, -2.0 ; second site: AP, $0.2 ; \mathrm{ML}, 2.0$; DV, -1.8 ; third site: AP, 0.2; ML, 3.0; DV, -4.0; forth site: AP, 0.2; ML, 3.0; DV, -3.5. After stereotaxic injection, mice were allowed to recover from anesthesia by subcutaneous application of a mixture with antipamezol, flumazenil, and naloxone. Infection efficiencies of rAAVs were routinely determined immunocytochemically using antibodies to the Flag tag or hrGFP or by analyzing the fluorescence of hrGFP or mCherry. Cell death induced by VP16-ATF3 was assessed $14 \mathrm{~d}$ after stereotaxic delivery of rAAV-VP16Atf3 and appropriate controls to the rat hippocampus. Rats were deeply anesthetized with an overdose of Nembutal, preperfused transcardially with PBS, and perfused with $200 \mathrm{ml}$ of neutral phosphate-buffered $10 \%$ formalin (Sigma). Brains were removed and postfixed overnight in the 
same fixative solution. For cryoprotection, brains were incubated in $20 \%$ sucrose in PBS for $2 \mathrm{~d}$. Brains were rapidly frozen on liquid nitrogen. Frozen sections ( $40 \mu \mathrm{m}$ thick) were collected in PBS. Consecutive sections separated by a $240 \mu \mathrm{m}$ distance were used for immunostaining and Fluoro-Jade C staining. Transgene expression was detected with antiFlag antibodies (1:2500, M2 mouse monoclonal; Sigma). Neuronal cell loss was assessed with neuronal nuclei (NeuN) immunostaining (1:500, mouse monoclonal; Millipore Bioscience Research Reagents). Immunostaining was done using standard procedures; staining with Fluoro-Jade C (Histo-Chem) was done as described previously (Schmued et al., 2005; Zhang et al., 2009).

Middle cerebral artery occlusion. Three weeks after stereotaxic delivery of rAAV or PBS to the left cortex, permanent middle cerebral artery occlusion (MCAO) was produced as described previously (Martinou et al., 1994; Zhang et al., 2005; Murikinati et al., 2010). Mice were placed in the recumbent position, anesthetized with $150 \mu \mathrm{l}$ of $2.5 \%$ tribromethanol per $10 \mathrm{~g}$ of body weight, and the animals were allowed to breathe spontaneously and were not ventilated. An incision was made from the left eye to the ear. When the temporal muscle was removed by electrocoagulation, the left middle cerebral artery (MCA) was visible through the semitranslucent temporal surface of the skull. After a small burr hole was made in the temporal bone with dental drill, the inner layer of the skull was removed with fine forceps and the dura mater was opened carefully to expose the left MCA. Care was taken to avoid damage to the brain tissue. Saline was present in the area surrounding the MCA. A microbipolar electrocoagulator was used to permanently occlude the left MCA. During surgical procedures, rectal temperature was maintained at $37 \pm$ $0.5^{\circ} \mathrm{C}$ with a temperature-controlled heat plate. After the incision was closed, mice were allowed to recover from anesthesia in their home cages where the temperature was maintained at $37^{\circ} \mathrm{C}$. In these conditions, animals were maintained homeothermically until fully recovery from anesthesia. Sham-operated mice were subjected to identical procedures without MCAO. On day 7 after MCAO or sham surgery, animals were killed under deep anesthesia with Narcoren and perfused intracardially with $20 \mathrm{ml}$ of normal saline. The brains were removed from the skull and immediately frozen on dry ice. Six consecutive 20 - $\mu \mathrm{m}$-thick coronal cryosections were cut every $400 \mu \mathrm{m}$ and subjected to cell death analysis and determination of total infarct volume using a silver staining technique (Herrmann et al., 2005). A total of $\sim 20$ slices were collected for each brain and analyzed for stroke volume. The silver-stained sections were scanned at 1200 dots per inch and the infarct area was measured by using ImageJ. Infarct volumes were corrected for brain edema as has been described previously (Herrmann et al., 2005). Surgery was performed and ischemic damage was measured by an investigator who had no knowledge of the treatment group or rAAV applied by stereotaxic injection. The MCAO model used in our study yielded reliable and very consistent results with $\sim 5 \mathrm{~mm}^{3}$ lesion volumes in shamtreated animals and $\sim 20 \mathrm{~mm}^{3}$ lesion volumes in MCAO-treated animals that have been injected stereotaxically with PBS.

Animals. The study was carried out in accordance with national guidelines for the use of experimental animals. The protocols used were approved by the governmental committees (Animal Care Committee, Regierungspräsidium Karlsruhe, Referat 35, Karlsruhe, Germany).

\section{Results}

\section{ATF3 is a target of the nuclear calcium-CREB signaling pathway}

To induce activity-dependent neuronal survival, we exposed a network of cultured hippocampal neurons to the $\mathrm{GABA}_{\mathrm{A}}$ receptor antagonist bicuculline. GABAergic interneurons, which represent $\sim 11 \%$ of the neuron population, impose a tonic inhibition onto the network (Arnold et al., 2005). Removal of $\mathrm{GABA}_{\mathrm{A}}$ ergic inhibition with bicuculline leads to action potential bursting, which stimulates calcium entry though synaptic NMDA receptors, generates robust cytoplasmic and nuclear calcium transients, induces CREBdependent transcription, and activates a prosurvival program (Hardingham et al., 2001, 2002; Arnold et al., 2005; Lee et al., 2005; Papadia et al., 2005; Zhang et al., 2007, 2009). QRT-PCR (Fig. 1A) and immunoblot analysis (Fig. $1 B$ ) show high levels of Atf 3 mRNA and ATF3 protein expression 2 and $4 \mathrm{~h}$ after inducing action potential bursting. Similar to $c$-fos, a classical neuronal activity- and calcium-regulated gene (Bading et al., 1993; Curran and Morgan, 1995), ATF3 induction by synaptic activity was blocked by the NMDA receptor antagonist MK-801 (Fig. $1 A, B$ ).

To determine a possible regulation of ATF3 by CREB and nuclear calcium signaling, we expressed in neurons the CREB inhibitor A-CREB (Ahn et al., 1998), a negative interfering mutant of CaMKIV [CaMKIV(K75E)] (Anderson et al., 1997; Lemrow et al., 2004) and the calmodulin (CaM) binding-peptide, CaMBP4 (Wang et al., 1995). CaMBP4 is a nuclear protein that contains four repeats of the M13 calmodulin binding peptide derived from the rabbit skeletal muscle myosin light chain kinase; it binds to and inactivates the nuclear calcium/CaM complex (Wang et al., 1995). We used rAAV-mediated gene transfer that resulted in expression of A-CREB, CaMKIV(K75E), CaMBP4, or hrGFP in $80-95 \%$ of the viable cells (Fig. 1D). Expression of A-CREB, CaMKIV(K75E), or CaMBP4, but not expression of hrGFP, inhibited ATF3 induction by synaptic activity (Fig. 1D). These results demonstrate that the Atf3 gene is regulated by a nuclear calcium signaling pathway involving CaMKIV and CREB. As expected, transcriptional induction of the $c$-fos gene, which is known to be controlled by nuclear calcium and CREB and by a calcium signaling pathway impinging on the serum response element in the c-fos promoter (Bading et al., 1993; Hardingham et al., 1997), was also attenuated by A-CREB, CaMKIV(K75E), or CaMBP4 (Fig. 1D). Consistent with a role of CREB in ATF3 regulation, we found that bath application of glutamate, which leads to a shut-off of CREB function via the activation of extrasynaptic NMDA receptors (Hardingham et al., 2002), failed to robustly induce ATF3 expression (Fig. 1C).

\section{CREB and MEF2 bind to the Atf 3 promoter}

DNA sequence analysis of the mouse Atf 3 promoter (Liang et al., 1996) revealed the presence of a CRE ( $5^{\prime}$-TTACGTCA-3') located at -93 to -86 bp $5^{\prime}$ of the transcriptional start site (Fig. $2 A$ ), raising the possibility that CREB directly interacts with the Atf 3 promoter. To determine whether Atf 3 is a direct CREB target, we carried out ChIP assays. Chromatin fragments from hippocampal neurons were immunoprecipitated with antibodies to CREB and analyzed by PCR using primers derived from the Atf 3 promoter. The CRE-containing fragment of the promoter was readily detectable in the ChIP assay, indicating that CREB binds to the Atf3 promoter (Fig. 2B).

In addition to the CRE, we noticed the presence of a canonical binding site for MEF2, 5'-CTATTAATAG-3' (McKinsey et al., 20020, in the Atf 3 promoter located immediately $5^{\prime}$ to the CRE (Fig. 2A). Similar to CREB, MEF2 has been implicated in activitydependent neuronal survival (Mao et al., 1999). ChIP assays using hippocampal neurons and antibodies to $\mathrm{MEF} 2 \mathrm{C}$ revealed that, indeed, MEF2C also binds to the proximal Atf3 promoter (Fig. 2C). Two other genes were included as positive controls in our ChIP assay. These were $c$-fos and Nur77, which are well characterized targets of CREB and MEF2C, respectively (Bading et al., 1993; Curran and Morgan, 1995; Youn et al., 2000). As expected, fragments of the promoter regions of the genes c-fos and Nur77, but not nucleolin (as a negative control), were present in the appropriate chromatin immunoprecipitates (Fig. 2B,C). No enrichment of any of the promoter fragments analyzed was observed when normal rabbit IgG was used for the immunoprecipitations (Fig. $2 B, C$ ). The results demonstrate that both CREB and MEF2C can bind to the regulatory region of the Atf3 gene. 
A

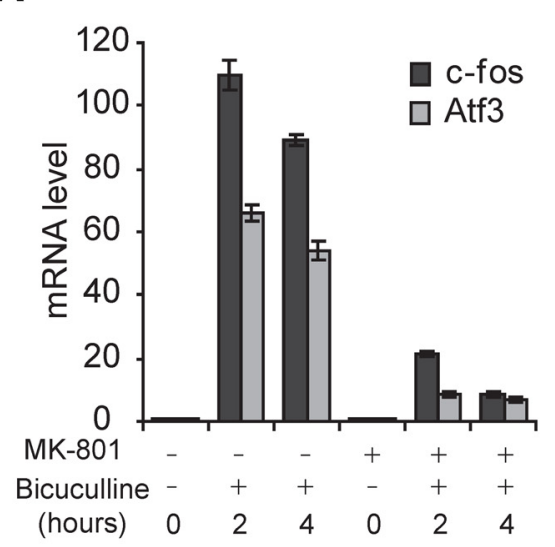

B

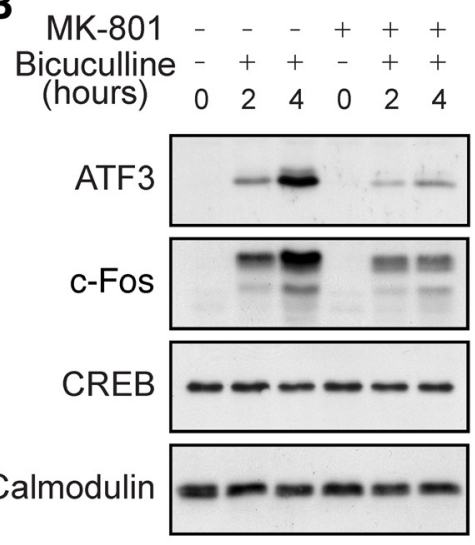

C

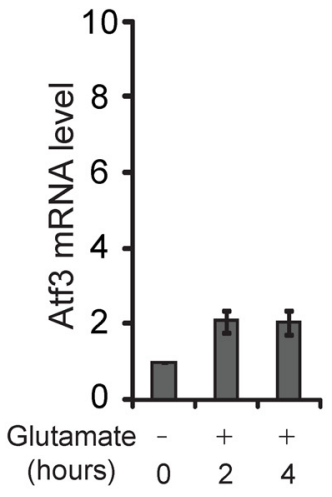

D
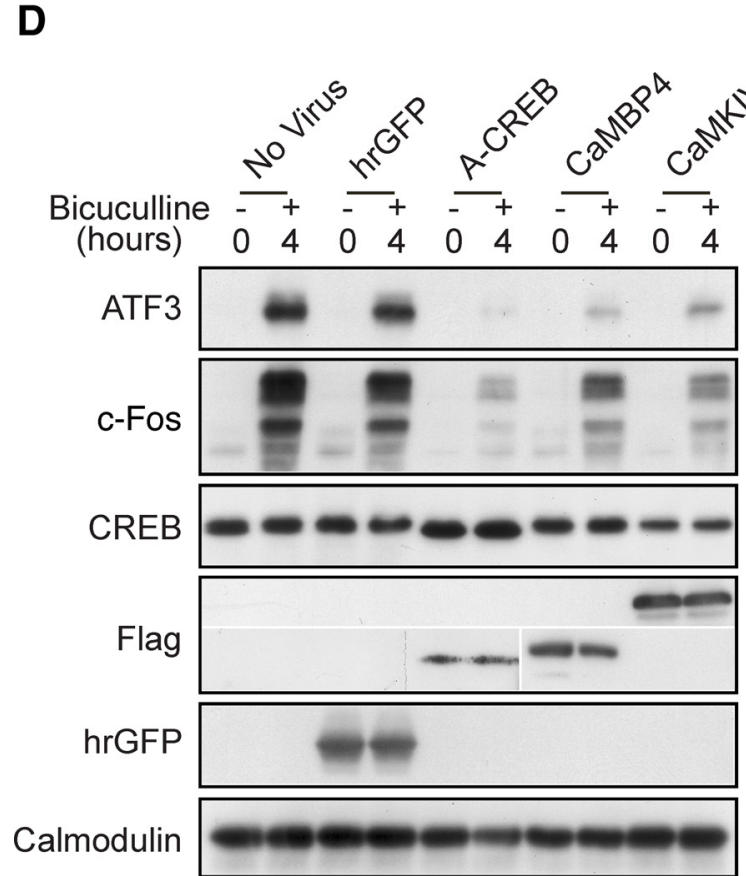

$E$

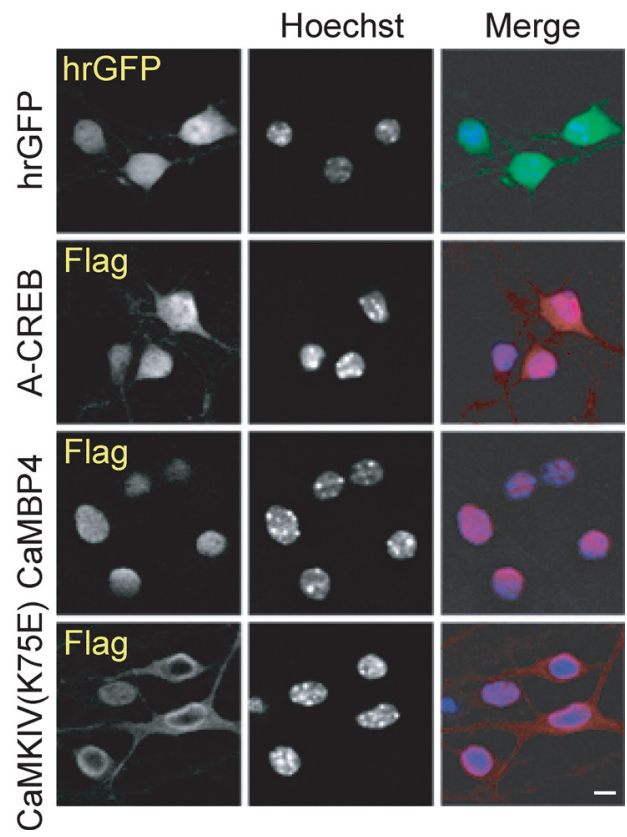

Figure 1. Activity-dependent regulation of $A t f 3$ expression is triggered by calcium entry through synaptic NMDA receptors and requires nuclear calcium signaling, CaMKIV, and CREB. $A, B, C$, QRT-PCR $(A, C)$ and immunoblot $(B)$ analyses of $A t f 3$ and $c$-fos expression in unstimulated hippocampal neurons and in hippocampal neurons treated for 2 and $4 \mathrm{~h}$ with bicuculline ( $50 \mu \mathrm{M})$ in the presence or absence of MK-801 $(10 \mu \mathrm{M})$ or treated for $4 \mathrm{~h}$ with glutamate $(20 \mu \mathrm{M})$. Bicuculline, a $\mathrm{GABA}_{\mathrm{A}}$ receptor antagonist, removes inhibitory synaptic activity from the neuronal network, leading to action potential bursting that is associated with robust increases in the cytoplasmic and nuclear calcium concentration (Hardingham et al., 2001; 2002; Arnold et al., 2005). Bars represent means \pm SEM $(n=3)$; the immunoblot shown is representative of four independent experiments. Calmodulin expression was used as the loading control. $\boldsymbol{D}$, Immunoblot analysis of ATF3 expression in uninfected hippocampal neurons and in hippocampal neurons infected with rAAVs expressing hrGFP, A-CREB, CaMBP4, or CaMKIV(K75E). Neurons were stimulated for $4 \mathrm{~h}$ with bicuculline $(50 \mu \mathrm{M})$ or left unstimulated. Expression of c-Fos, (REB, hrGFP, and calmodulin (loading control) was analyzed in parallel. A-CREB, CaMBP4, and CaMKIV(K75E) are Flag tagged and were detected with an antibody to the Flag; hrGFP was detected with an antibody to hrGFP. A representative example of four independent experiments is shown. $\boldsymbol{E}$, Immunocytochemical analysis of hippocampal neurons infected with rAAVs expressing hrGFP, A-CREB, CaMBP4, or CaMKIV(K75E). Expressed proteins were detected immunocytochemically using an antibody to hrGFP or with an antibody to Flag for the Flag-tagged proteins A-CREB, CaMBP4, and CaMKIV(K75E). Nuclei of cells were counterstained with Hoechst 33258. Representative images are shown. Scale bar, $5 \mu \mathrm{m}$.

To investigate whether CREB and MEF2C are sufficient to increase expression of ATF3, we infected hippocampal neurons with rAAVs carrying VP16-CREB or VP16-MEF2C, which, because of their fusion to VP16, a herpes simplex virus-encoded transcriptional activator protein, represent constitutively active versions of CREB and MEF2C, respectively. Expression of either VP16-CREB or VP16-MEF2C caused an increase in ATF3 expression (Fig. 2D). Coexpression of VP16-CREB and VP16MEF2C gave the strongest increase in ATF3 expression (Fig. 2D), indicating that both factors can act together to control the Atf 3 promoter. We also observed robust increases in ATF3 expression in neurons expressing CaMKIV(1-313), a constitutively active form of CaMKIV that stimulates CREB-mediated transcription (Sun et al., 1994) (Fig. 2D).

As a complementary approach to assess the role of the CRE and the MEF2 binding site in Atf3 regulation, we constructed and functionally tested a series of Atf 3 promoter-containing luciferase reporter genes. The wild-type reporter construct (Atf3-luc) consists of a firefly luciferase reporter gene driven by an 81-bp-long sequence of the mouse Atf3 promoter harboring a TATA box, a MEF2 binding site (MRE), and a CRE. Mutations were introduced into the CRE or the MRE individually or in combination to generate reporter constructs lacking binding sites for CREB (Atf3 $\mathrm{CRE}-\mathrm{luc}), \mathrm{MEF} 2$ (At $3 \Delta \mathrm{M}$ MRE-luc), or both tran- 
A

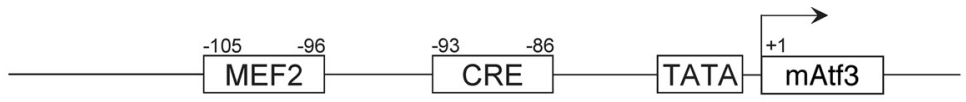

\begin{tabular}{|c|c|c|c|c|}
\hline & ;TATTAATAG & & TTACGTCA & TTTAA \\
\hline & & & & \\
\hline & CTATTAATAG & & TTACGTCA & \\
\hline
\end{tabular}

B

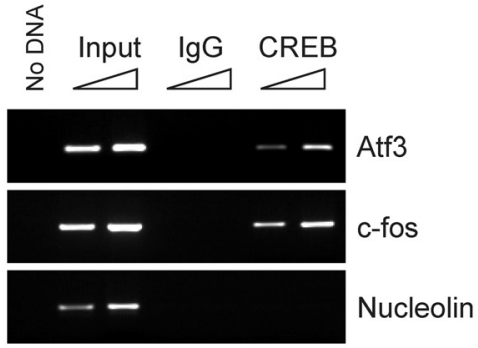

C
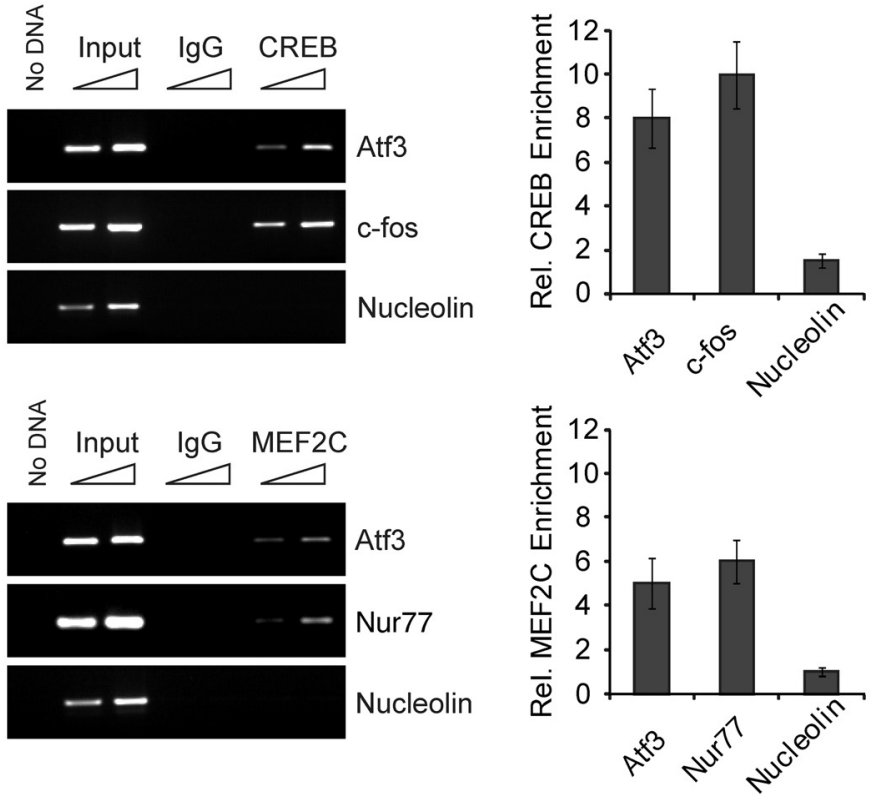

D

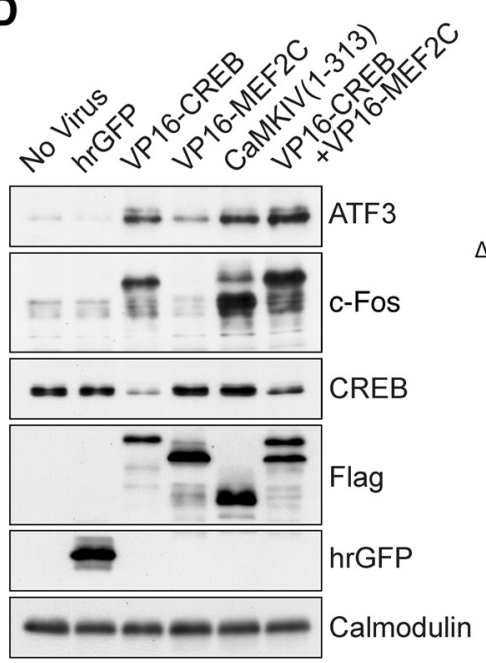

E

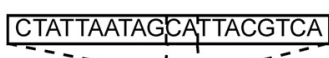

wt -

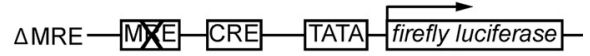

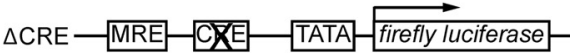
$\triangle M R E, \triangle C R E-$ MXE-CXE-TATA CTATTGCGAGCATTTGGTCA

$\mathbf{F}$

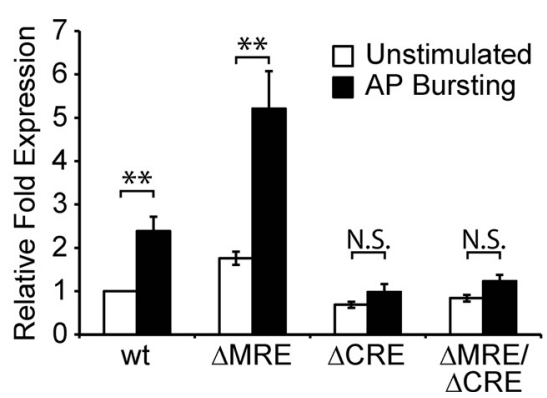

Figure 2. CREB and MEF2C bind to the Atf 3 promoter and are sufficient to activate Atf3 expression. $A$, Schematic representation of the proximal promoter of the mouse $A t f 3$ gene $(\mathrm{m} A t \mathrm{~A} 3)$. Sequences of the MEF2 and $C R E B$ binding sites and the TATA box are given; the start site

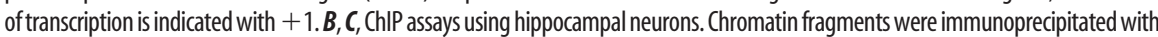
antibodies to CREB or MEF2C or with normal rabbit $\operatorname{lgG}(\operatorname{lgG})$, and genomic DNA fragments were eluted and amplified using PCR with primers specific to the promoters of Atf3, c-fos, and Nur77 (a known MEF2C target gene) (Youn etal., 2000). ChIP assays were quantified and expressed as enrichment relative to $\lg G$ control. As positive control for the $P C R$, we used 0.1 and $0.3 \%$ of the sheared chromatin before immunoprecipitation (indicated as Input); for negative control, the PCR was done without adding chromatin (No DNA) or with primers to the Nucleolin promoter. $\mathbf{D}$, Immunoblot analysis of ATF3 expression in uninfected hippocampal neurons and in hippocampal neurons infected with rAAVs expressing hrGFP, VP16-CREB, VP16-MEF2C, or CaMKIV(1-313). Expression of c-Fos, CREB, hrGFP, and calmodulin (loading control) was analyzed in parallel. VP16-CREB, VP16-MEF2C, and CaMKIV(1-313) are Flag tagged and were detected with an antibody to the Flag; hrGFP was detected with an antibody to hrGFP. A representative example of four independent experiments is shown. $E, F$, Analysis of luciferase activity in cell extracts from unstimulated and stimulated hippocampal neurons cotransfected with the indicated pGL4.10-based Atf3-luc reporter constructs. A schematic diagram of the used reporter constructs is shown (E). Neurons were stimulated $24 \mathrm{~h}$ posttransfection for $48 \mathrm{~h}$ using bicuculline $(50 \mu \mathrm{m})$ and $4-\mathrm{AP}(250 \mu \mathrm{m})$. A basic expression cassette for humanized Renilla luciferase (pGL4.70) was used to normalize for transfection efficiency. AP, Action potential. Experiments were done in duplicate and data represent mean values $\pm \operatorname{SEM}(n=4)$. Statistical analysis was determined by ANOVA $\left({ }^{* *} p<0.01\right.$; N.S. indicates not significant) $(\boldsymbol{F})$.

scription factors (Atf3 $\mathrm{CRE} \Delta \mathrm{MRE}-\mathrm{luc}$ ) (Fig. $2 E)$. These constructs were transfected into hippocampal neurons and tested for their regulation by AP bursting. We found that expression of both Atf3-luc and Atf $3 \Delta$ MRE-luc was induced by action potential bursting. In contrast, expression of the two reporter constructs that lack the CRE (i.e., Atf $3 \Delta$ CRE-luc and Atf $3 \Delta$ CRE $\Delta$ MRE-luc) did not significantly change after action potential bursting (Fig. $2 F)$. This identifies the CRE as the principal DNA regulatory element in the Atf3 promoter that mediates the induction of Atf 3 following synaptic activity. The presence of the MRE in the reporter constructs seems to have a moderate suppressive effect on the action potential bursting-induced transcriptional response, since a lack of the MRE slightly enhanced expression of the CREcontaining reporter under basal and stimulated conditions. Given the close proximity of the MRE and the CRE (which are separated by only $2 \mathrm{bp}$ ), one possible explanation of this observation is that the binding of MEF2 to the MRE could, through steric hindrance, affect the binding and/or activation of CREB.

Collectively, these findings indicate that the Atf3 gene is not only a direct target of CREB but may serve as a converging point for at least two survival promoting transcription factors. However, the two transcription factors do not appear to contribute equally to ATF3 regulation in hippocampal neurons. First, VP16-CREB is a stronger inducer of ATF3 expression than VP16-MEF2C (Fig. 2D). Second, whereas CREB is both necessary and sufficient for Atf3 regulation (Figs. $1 D, 2 D)$, we found that expression in hippocampal neurons of three different dominant-negative mutants of MEF2C [i.e., MEF2C(R24L) and MEF2C(S388A) (Han et al., 1997; Molkentin et al., 1996) and MEF2C(R24L/S388A) (data not shown)] did not significantly inhibit activitydependent regulation of Atf3 (data not shown). Finally, the reporter gene assays suggest that the CRE in the proximal Atf3 promoter is the major site for activitydependent transcriptional regulation of Atf3. Thus, MEF2C can interact with the Atf3 promoter and is capable of increasing Atf3 expression when fused to VP16. However, in contrast to CREB, in hippocampal neurons MEF2C activation does not seem to be required for $A t f 3$ induction by synaptic activity.

\section{ATF3 acts antiapoptotically}

We next investigated the ability of ATF3 to protect against apoptosis. To assess apoptotic cell death, two types of assays were 
used: growth factor withdrawal and treatment with a low concentration of staurosporine (Hardingham et al., 2002; Papadia et al., 2005). We found that compared to control (i.e., noninfected neurons or infection with rAAV-hrGFP), cell death induced by either growth factor withdrawal or staurosporine treatment was inhibited in neurons infected with rAAV carrying Flag-tagged ATF3 (Fig. $3 A, B)$. In the case of growth factor withdrawal, inhibition of apoptosis by ATF3 was $94 \pm 8 \%(n=4)$; indeed, in ATF3 overexpressing neurons the percentage of cell death obtained after growth factor withdrawal is not statistically different from the cell death obtained in the control group that was grown in the presence of growth factors (Fig. 3A). For staurosporineinduced cell death a somewhat less effective inhibition of $40 \pm 4 \%(n=4)$ was observed in ATF3-overexpressing neurons (Fig. 3B).

\section{ATF3 protects against excitotoxicity induced by NMDA exposure or OGD} To assess a possible neuroprotective potential of ATF3 in excitotoxicity, we used two experimental conditions: bath application of $20 \mu \mathrm{M}$ NMDA or exposure of hippocampal neurons to a medium containing low oxygen and no glucose, a procedure known as oxygen-glucose deprivation or OGD. Similar to the re-

sults obtained for apoptotic cell death, we found that compared to control (i.e., noninfected neurons or infection with rAAV-hrGFP), cell death induced by either NMDA bath application or by OGD was inhibited in neurons infected with rAAV carrying Flag-tagged ATF3 (Fig. 3C,D). These results demonstrate that ATF3 can confer robust neuroprotection, rendering neurons more resistant to apoptosis- and necrosisinducing conditions.

\section{Gene repression by ATF3 is neuroprotective: VP16-ATF3} kills neurons

We next investigated whether the known transcriptionrepressing activity of ATF3 (Chen et al., 1994) accounts for the observed neuroprotection. To confirm that ATF3 expression in hippocampal neurons leads to repression of target genes, we transfected hippocampal neurons with a luciferase reporter gene, pGL2-5 $\times$ Gal4-TK-luc, which contains the thymidine kinase (TK) promoter and a binding site for the yeast DNA binding protein, Gal4 (Fujita et al., 2004). Because of the presence of the TK promoter (which is constitutively active), we could readily detect luciferase activity in extracts obtained from hippocampal neurons transfected with pGL2-5×Gal4-TK-luc (Fig. 4A). A severalfold increase in reporter gene expression was observed in hippocampal neurons transfected with pGL2-5×Gal4-TK-luc alongside an expression vector for the transcriptional activation domain of NF- $\kappa \mathrm{B}$ fused to the Gal4 DNA binding protein (Fig. $4 A$ ). In contrast, in hippocampal neurons cotransfected with pGL2-5×Gal4-TK-luc and an expression vector for Gal4-ATF3, significantly less luciferase activity was detected compared to the appropriate controls (Fig. 4A). Expression of a Gal4-dsRED fusion protein had

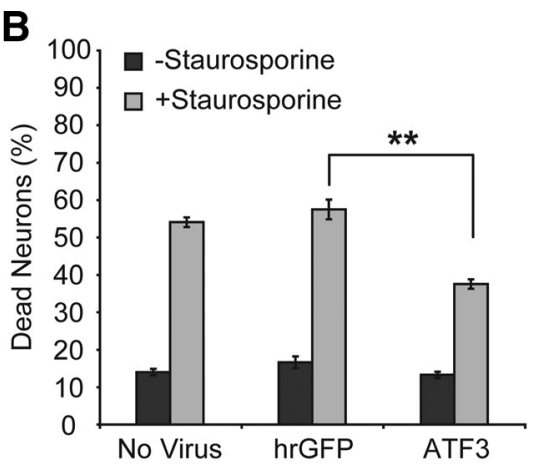

D

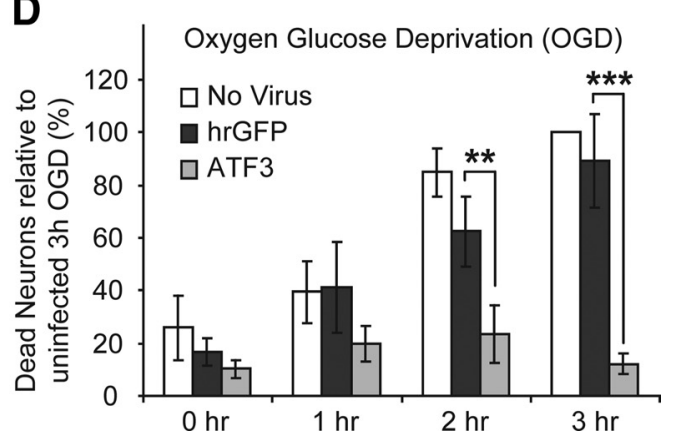

Oxygen Glucose Deprivation (OGD)

+NMDA

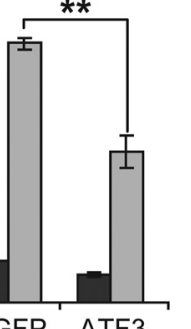

$\mathrm{Ohr}$

$1 \mathrm{hr}$

$2 \mathrm{hr}$

$3 \mathrm{hr}$

Figure 3. ATF3 protects against apoptosis and excitotoxicity. $\boldsymbol{A}-\boldsymbol{D}$, Analysis of cell death induced by growth factor withdrawal was assessed using morphological criteria (for details, see Materials and Methods). Statistical significance was deter作 no effect on reporter gene expression (Fig. $4 A$ ). These results indicate that ATF3 bound to the promoter of target genes (in case of the pGL2-5×Gal4-TK-luc, via the Gal4 DNA binding domain) causes suppression of gene transcription.

To determine whether neuroprotection caused by ATF3 is due to ATF3-mediated transcriptional repression, we fused the herpes simplex virus transcription activation domain VP16 to ATF3. We reasoned that if $\mathrm{ATF} 3$ promotes survival through repression of putative prodeath genes, its conversion to a transcriptional activator (by means of fusion to VP16) transforms ATF3 into a prodeath protein. We found that indeed expression of VP16ATF3 in cultured hippocampal neurons dramatically enhanced cell death (Fig. $4 B, C$ ). This prodeath activity required the ATF3 portion of the VP16-ATF3 fusion protein and was not caused by the expression of the VP16 domain per se, because expression of another VP16 fusion protein, VP16Npas4, did not increase cell death (see Fig. 5C). Using time lapse video microscopy of hippocampal neurons expressing VP16-ATF3 (alongside EGFP for visualization), we observed in all cells analyzed $(n=22)$ the formation of many thin dendritic membrane protrusions as the earliest detectable morphological change in the cell death process. These protrusions or "death villi" may emerge from the dendritic shaft or from spines; they give rise to a "frayed" appearance of the neurons that is transient (lasting no longer than $4 \mathrm{~h}$ ) and precedes the swelling and subsequent fragmentation of the dendrites (Fig. 4D,E). The cell death induced by VP16-ATF3 may occur via an apoptotic pathway, since it was inhibited by the broad spectrum caspase inhibitor Z-VAD-FMK (Fig. 5A). Moreover, the nucleus from hippocampal neurons expressing 
A

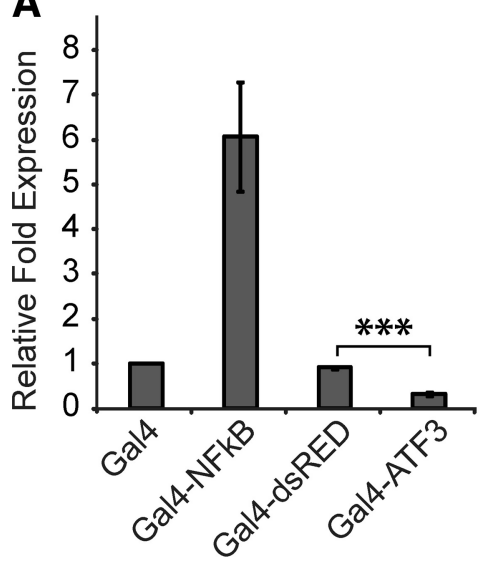

B

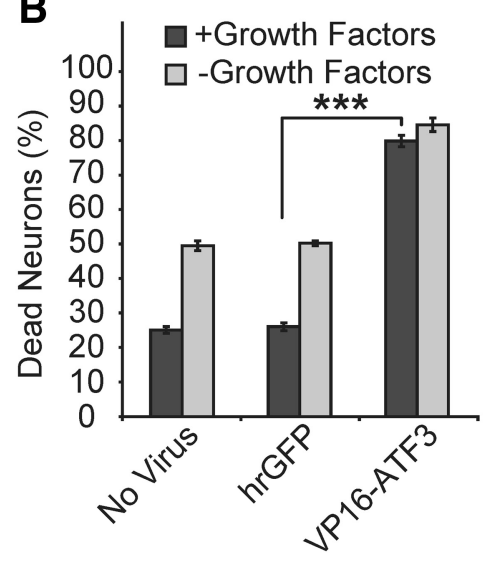

C

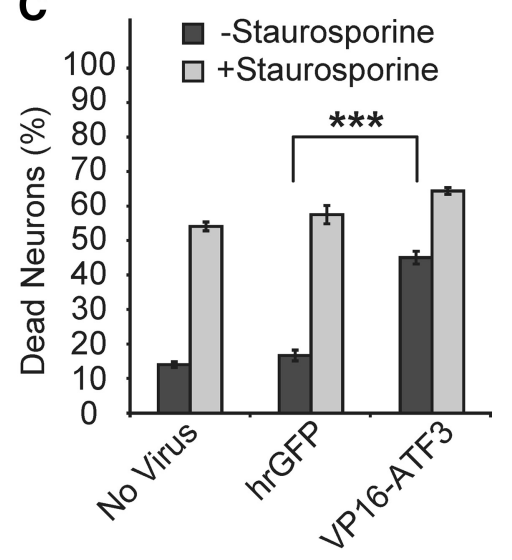

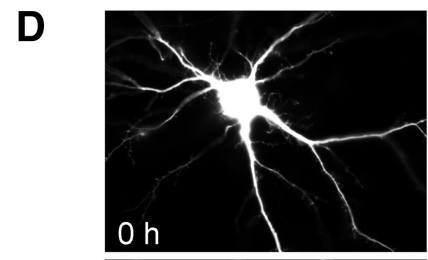
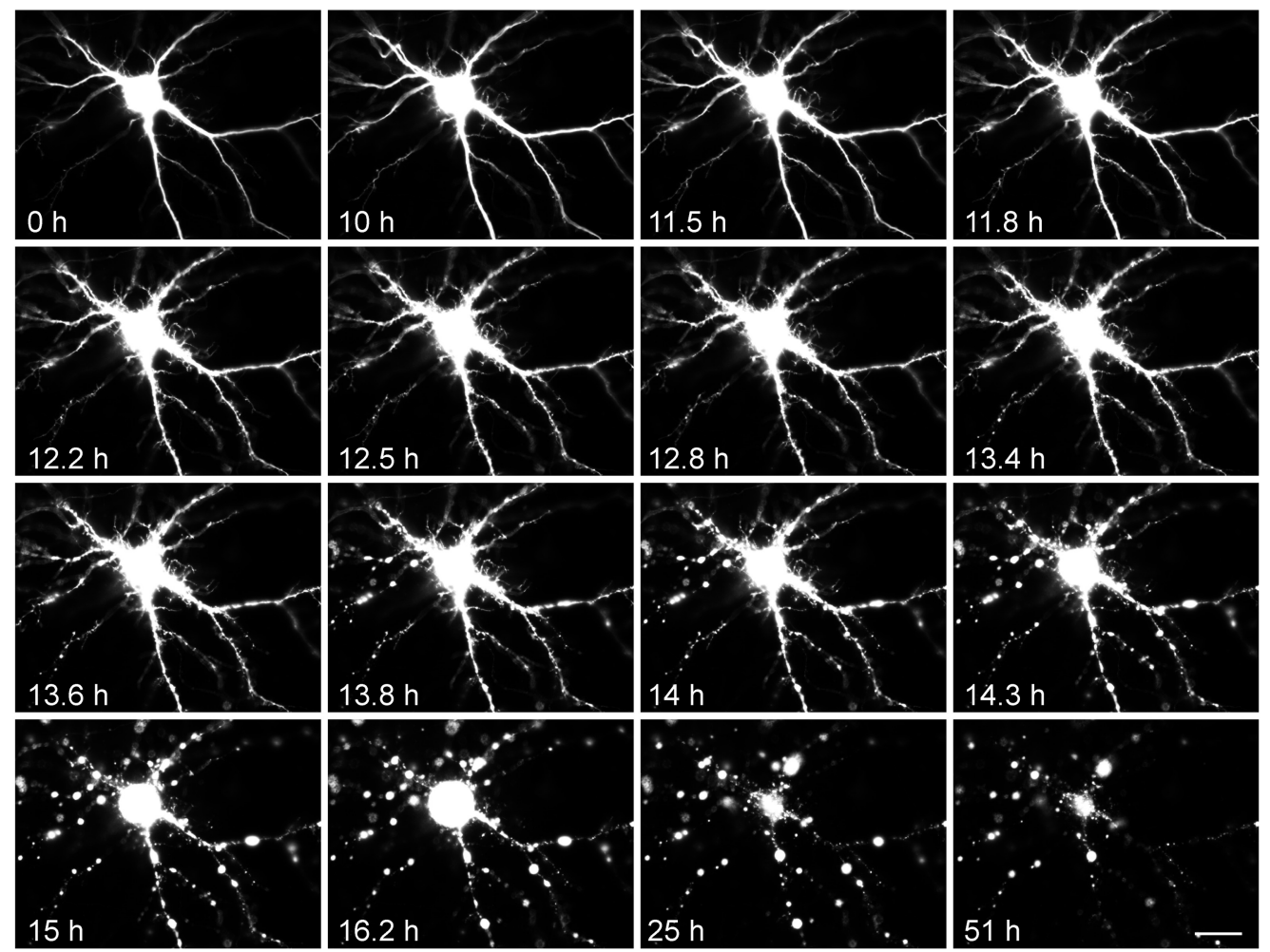

$\mathbf{E}$
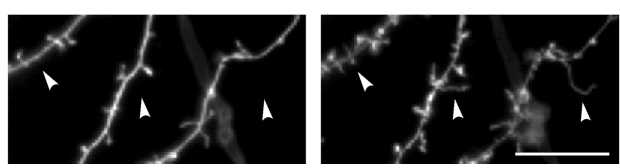

Figure 4. ATF3 acts as a repressor of transcription to promote neuronal survival; VP16-ATF3 kills neurons. A, Analysis of luciferase activity in cell extracts from hippocampal neurons cotransfected with pGL2-5×Gal4-TK-luc and expression vectors for the indicated Gal4 fusion proteins. An rAAV plasmid containing an expression cassette for humanized Renilla luciferase, rAAV-hrLuc, was used to normalize for transfection efficiency. Experiments were done in duplicate; data represent mean values \pm SEM $(n=4)$. Statistical analysis was determined by ANOVA; statistically significant differences are indicated with asterisks ( $\left.{ }^{* * *} p<0.001\right) . B, C$, Analysis of cell death in uninfected hippocampal neurons and in hippocampal neurons infected with rAAVs expressing hrGFP or VP16-ATF3. Bars represent means \pm SEM $(n=$ 3). Statistical significance was determined by ANOVA; statistically significant differences are indicated with asterisks $(* * * 00.001)$. Cell death induced by growth factor withdrawal $(\boldsymbol{B})$ or staurosporine $(10 \mathrm{~nm})$ treatment $(\boldsymbol{C})$ is shown for comparison. The infection rates ranged from 80 to $95 \%$ of the neurons; they were determined by analyzing the fluorescence of hrGFP or immunocytochemically using antibodies to hrGFP or Flag that labels cells expressing Flag-tagged VP16-ATF3. Expression of other VP16 fusion proteins, including VP16-CREB or VP16-MEF2, did not increase the rate of cell death in similar experiments (data not shown). Cell death was assessed using morphological criteria (for details see Materials and Methods). D, Time lapse video microscopy of a hippocampal neuron transfected on $10 \mathrm{DIV}$ with an rAAV plasmid harboring two synapsin I promoter-containing expression cassettes for VP16-ATF3 and EGFP, respectively. EGFP fluorescence was monitored for $\sim 57 \mathrm{~h}$ starting $16 \mathrm{~h}$ after transfection. Images taken at the indicated times are shown; scale bar, $15 \mu \mathrm{m}$. E, High-magnification images of a hippocampal neuron transfected and imaged as in D showing death signaling-associated membrane protrusions (death villi) at $\sim 21 \mathrm{~h}$ after the start of the imaging; arrows indicate position of newly formed death villi. The pictures show the same dendritic section with a time difference of $1 \mathrm{~h}$. Scale bar, $8 \mu \mathrm{m}$.

VP16-ATF3 were TUNEL positive and contained large round chromatin clumps, a morphological characteristic of apoptosis (Fig. $5 B$ ). We also analyzed the possible prodeath activity of VP16-ATF3 in vivo. Similar to the result obtained in vitro, we observed severe hippocampal cell death in vivo 2 weeks after stereotaxic delivery of an rAAV containing an expression cassette for VP16-ATF3 to the hippocampus of adult rats (Fig. $5 C$ ). These results suggest that the neuroprotective activity of 
A

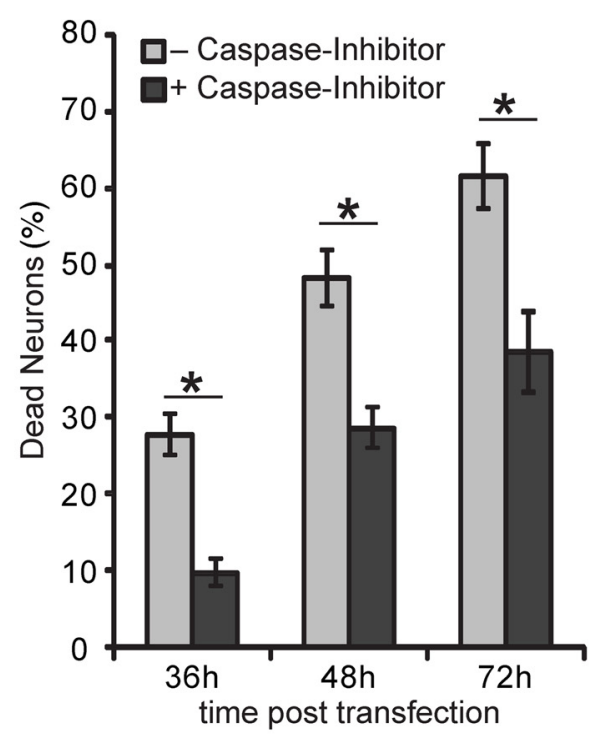

C

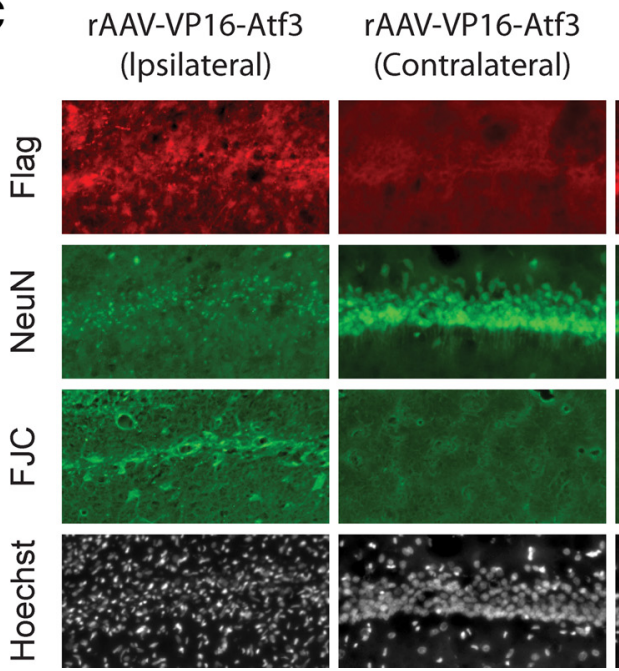

B

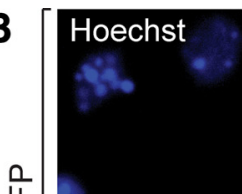

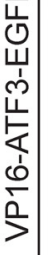
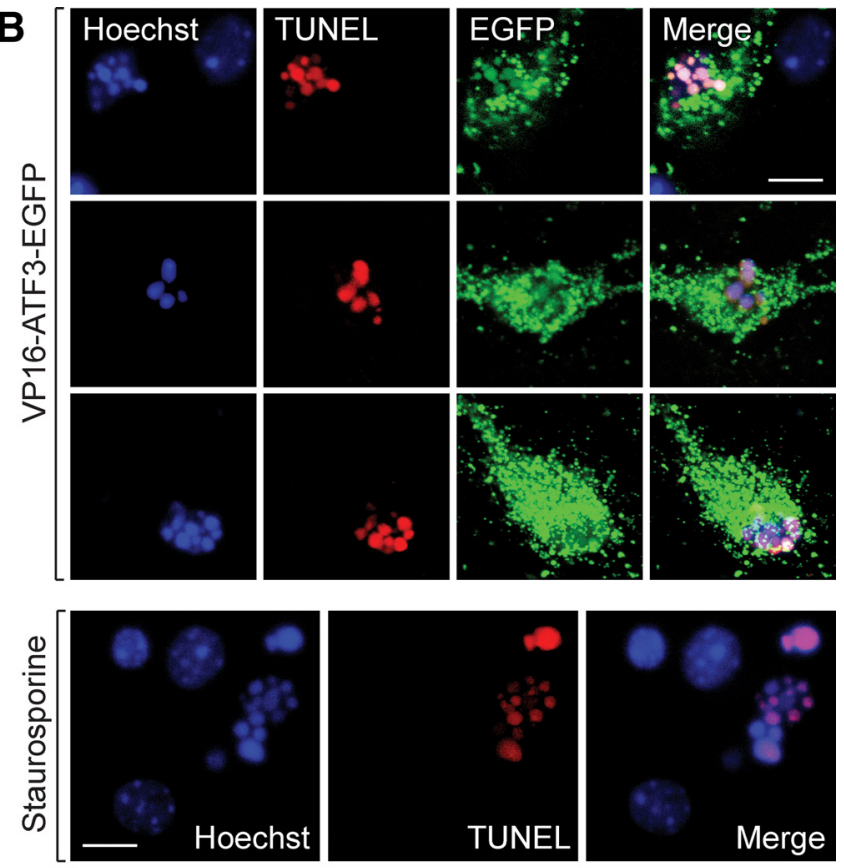

rAAV-VP16-Npas4

rAAV-Atf3 (Ipsilateral) (Ipsilateral)
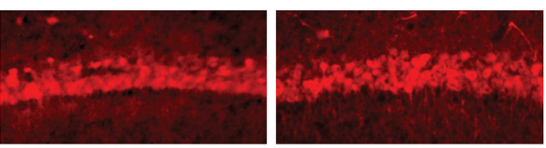

rAAV-mCherry

(Ipsilateral)
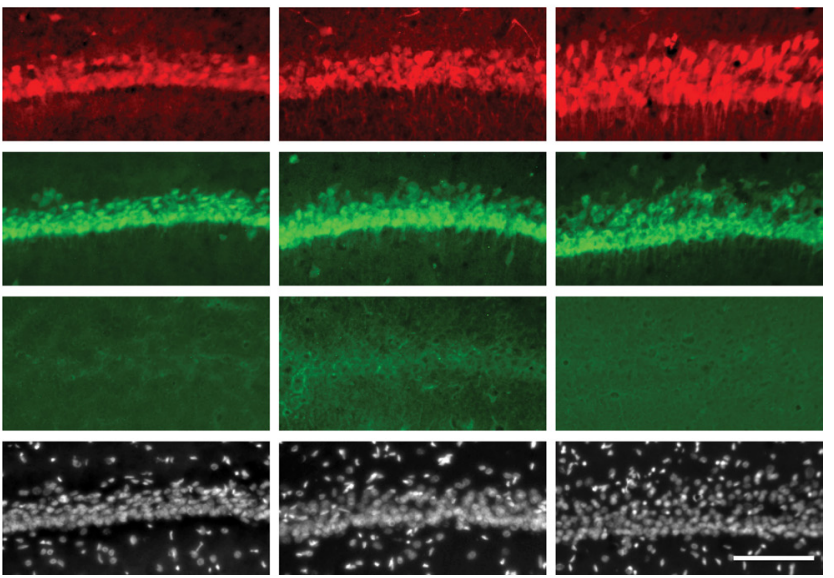

Figure 5. VP16-ATF3 and apoptosis. A, Analysis of cell death in hippocampal neurons induced by VP16-ATF3 in the presence or absence of the caspase inhibitor Z-VAD-FMK. After transfection on 10 DIV with an rAAV plasmid harboring two synapsin I promoter-containing expression cassettes for VP16-ATF3 and EGFP, respectively, hippocampal neurons were treated with $100 \mu \mathrm{m} Z$-VAD-FMK or were left untreated. Cell death was assessed 36, 48, and $72 \mathrm{~h}$ after transfection using morphological criteria (for details, see Materials and Methods); transfected neurons were identified by analyzing the fluorescence of EGFP. Bars represent means $\pm \operatorname{SEM}(n=3)$. Statistical significance was determined by Student's $t$ test; statistically significant differences are indicated with an asterisk $\left({ }^{*} p<0.05\right)$. B , TUNEL and Hoechst 33258 staining of hippocampal neurons. Top, Neurons transfected as in $\boldsymbol{A}$ to express VP16-ATF3 and EGFP were stained 36,48 , and $72 \mathrm{~h}$ after transfection; transfected neurons were identified by analyzing the fluorescence of EGFP. Bottom, Hippocampal neurons undergoing apoptotic cell death after a $36 \mathrm{~h}$ treatment with $10 \mathrm{~nm} \mathrm{staurosporine} \mathrm{are} \mathrm{shown}$ for comparison. Photomicrographs of representative images are shown. Scale bars, $10 \mu \mathrm{m}$. C, Analysis of cell death in the CA1 region of the hippocampus of animals 2 weeks after unilateral stereotaxic injection of rAAV-VP16-Atf3 (expressing Flag-tagged VP16-ATF3), rAAV-VP16-Npas4 (expressing Flag-tagged VP16-Npas4), rAAV-Atf3, or rAAV-mCherry. Degenerating neurons and cell loss were assessed using Fluoro-Jade ( labeling (FJC) and NeuN immunoreactivity. VP16-ATF3, detected on the ipsilateral (i.e., injected) hemisphere using the antibody to the Flag tag, caused widespread neuronal cell loss (indicated by a decrease in NeuN immunoreactivity and strong Fluoro-Jade ( staining). The contralateral (i.e., noninjected) hemisphere of the animals injected with rAAV-VP16-Atf3 and the ipsilateral (i.e., injected) hemisphere of the animals injected with rAAV-VP16-Npas4, rAAV-Atf3, or rAAV-mCherry displayed little Fluoro-Jade C staining and are shown for comparison. Nuclei of cells were counterstained with Hoechst 33258. Representative examples are shown of the following: rAAV-VP16-Atf3, $n=7 ; \mathrm{rAAV}-\mathrm{VP16}$-Npas4, $n=4 ; \mathrm{rAAV}-\mathrm{Atf3}, n=7$; rAAV-mCherry, $n=4$. Scale bar, $100 \mu \mathrm{m}$.

ATF3 is caused by transcriptional repression and that the conversion of ATF3 to a transcriptional activator kills neurons.

ATF3 confers neuroprotection in a mouse stroke model

We finally analyzed the ability of ATF3 to protect neurons from cell death in a mouse stroke model (Fig. 6A). Ischemic conditions were induced by middle cerebral artery occlusion or MCAO (Zhang et al., 2005). Ischemic brain injury affects many brain regions, in particular the cerebral cortex. We first established a suitable delivery protocol for rAAVs to the cortex of young adult mice. We found that a line shot stereotaxic delivery to the mouse cortex of a high-titer virus solution consistently gave rise to a widespread expression of the transgene in the cerebral cortex (Fig. 6B,E; supplemental Fig. 1, available at www.jneurosci.org as supplemental material). For details on the stereotaxic delivery, see Materials and Methods. Three weeks after stereotaxic delivery 
A

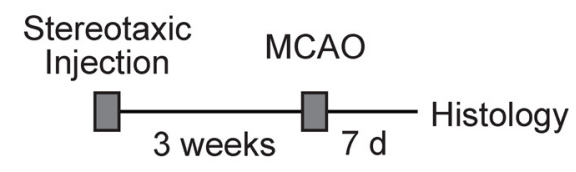

B

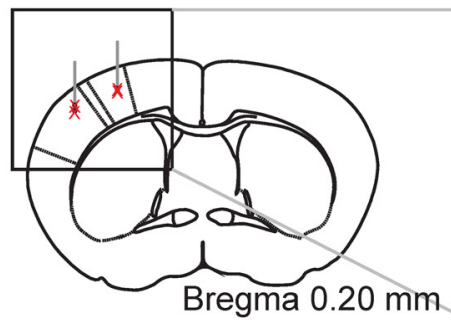

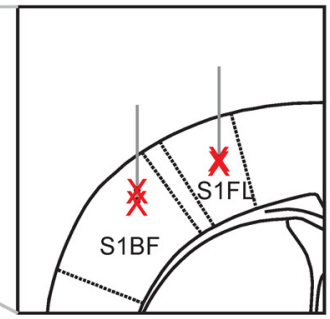

D
C

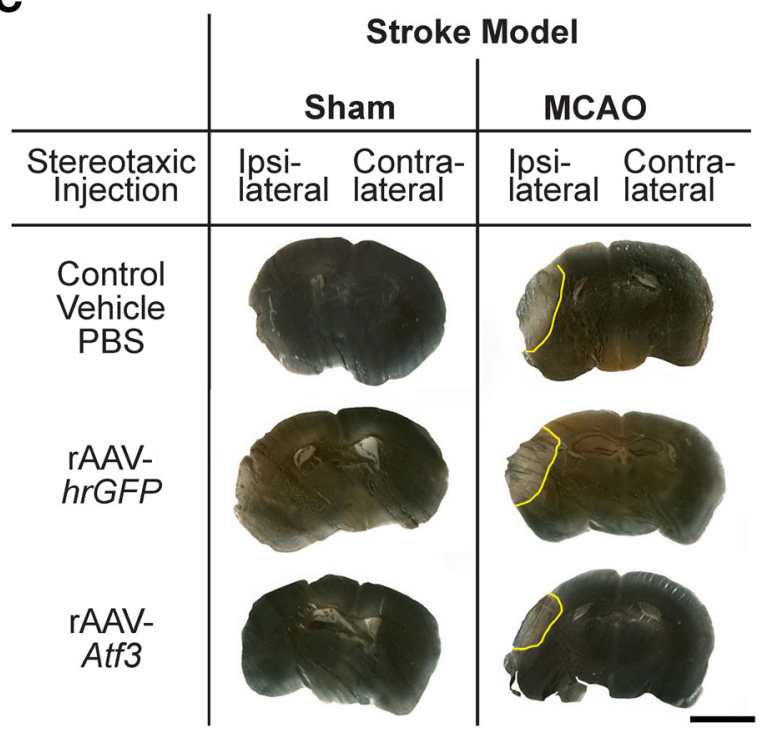

E

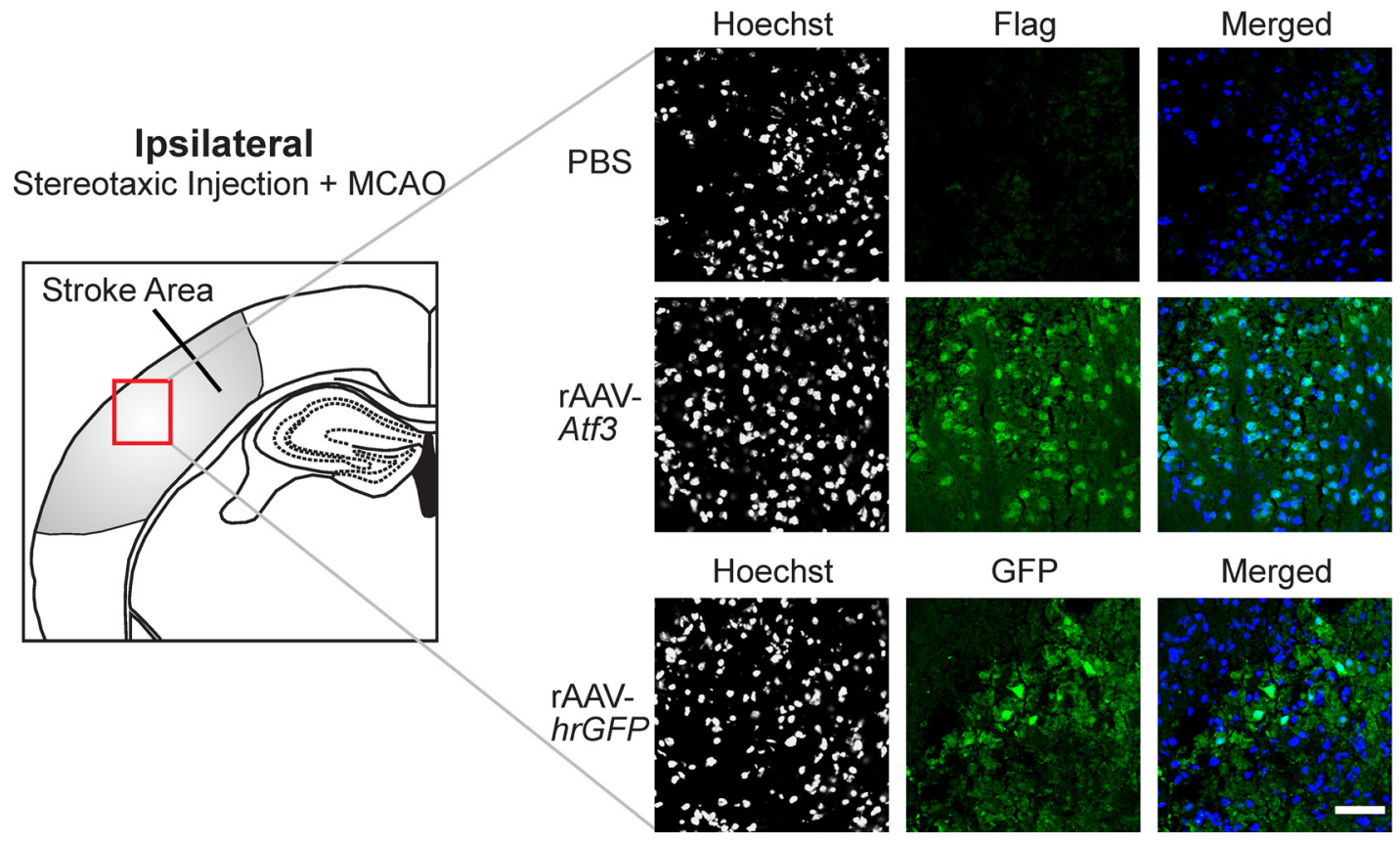

Figure 6. ATF3 protects neurons from stroke-induced brain damage. $A, B$, Scheme for MCAO $(A)$ and schematic representation of the site of stereotaxicdelivery of PBS, rAAV-hrGFP, or rAAV-Atf3 (B). Animals were stereotaxically injected by a double line shot into the primary somatosensory cortex barrel field (S1BF) and the primary somatosensory cortex forelimb region (S1FL) (B). $C$, Silver-stained coronal brain sections of the three different stereotaxic injection groups used to analyze infarct size in MCAO and sham-treated mice. Representative images from a series of 20 slices per brain of the ipsilateral hemisphere (i.e., injected, lefthemisphere) and the contralateral hemisphere (i.e., noninjected, right hemisphere) are shown. Stereotaxic injections were into the lefthemisphere. The border of the damaged area is indicated with a yellow line. Scale bar, $0.25 \mathrm{~cm}$. D, Quantitative analysis of infarct volume using 20 silver-stained coronal brain sections per animal obtained from mice 7 dafter onset of MCA0 or sham. Mice were stereotaxically injected into the left cortex with PBS, rAAV-hrGFP, or rAAV-Atf3 3 weeks before MCA0 or had undergone sham surgery. Statistical analysis was determined by ANOVA; statistically significant differences are indicated with an asterisk $\left({ }^{*} p<0.05\right)$.E, Detection of transgene expression in coronal sections from mice stereotaxically injected into the left cortex with PBS, rAAV-hrGFP, or rAAV-Atf3 and subjected to MCAO. A schematic representation of the area of histological analysis is shown. Representative images of the hrGFP fluorescence and immunostainings using antibodies to Flag that label cells expressing Flag-tagged ATF3 are shown. Nuclei of cells were counterstained with Hoechst 33258. Scale bar is $50 \mu \mathrm{m}$. 
of rAAV-Atf3, mice underwent MCAO. Seven days after MCAO, mouse brains were analyzed histochemically to detect the heterologously expressed proteins (i.e., ATF3 and hrGFP), and silver staining (Herrmann et al., 2005) was used to mark the damaged brain area (Fig. $6 C-E$ ). In the control group (i.e., mice stereotaxically injected with rAAV-hrGFP or PBS), MCAO induced severe damage in the cerebral cortex (Fig. 6C,D). However, in mice that had been stereotaxically injected with $\mathrm{rAAV}-\mathrm{Atf} 3$, we observed a reduction in brain damage in the cerebral cortex. Quantification of the results revealed that compared to controls, stroke-induced damage of the cerebral cortex is reduced by $\sim 41 \%$ by the expression of ATF3 (Fig. 6D).

\section{Discussion}

In this study, we established a synaptic activity-regulated signaling module that consists of nuclear calcium-CREB-ATF3 and links synaptic NMDA receptors to a gene repression program that protects neurons against apoptosis and cell death induced by extrasynaptic NMDA receptors.

\section{CREB-ATF3: a hierarchical transcription factor network controls neuronal survival}

The importance of CREB in neuronal survival is well established (Riccio et al., 1999; Mantamadiotis et al., 2002; Hardingham et al., 2002; Lee et al., 2005; Papadia et al., 2005). However, CREB has many other roles in the nervous system, particularly in the context of learning, memory, addiction, and neurogenesis (Carlezon et al., 1998; Silva et al., 1998; Lonze and Ginty, 2002; Zhu et al., 2004; Giachino et al., 2005). The results of this study suggest that CREB may exert its different biological functions by activating target genes that act, in a hierarchical transcription factor network, downstream of CREB as regulators of function-specific genomic subroutines. We identified Atf 3 as such a regulator of neuronal survival. Atf3 promoter analysis and chromatin immunoprecipitation experiments revealed that $A t f 3$ is not only a direct target of CREB but also a target of MEF2. Similar to CREB, MEF2 is also a multifunctional transcription factor with a prominent role in activity-dependent neuronal survival (Mao et al., 1999; McKinsey et al., 2002). Thus Atf3 may serve as a converging point of several survival-promoting transcription factors. The sequential activation of multifunctional and function-specific transcriptional regulators may be a more widely used strategy to implement other adaptive responses, such as synaptic plasticity, in which CREB has been implicated.

\section{Synapse dysfunction compromises nuclear calcium signaling: are neurodegenerative diseases "nuclear calciopathies"?}

The vital role for neuronal activity and synaptic NMDA receptors in activating neuroprotection through nuclear calcium-CREBATF3 signaling suggests that intact synaptic transmission may be critical for the well-being of neurons. Under conditions of compromised synaptic transmission, neurons may slowly degenerate and eventually die, which could explain the observed cell death in neurodegenerative disorders that are associated with a loss of synapses. This may be particular relevant for Alzheimer's disease (AD), which is characterized by a reduction in synapse density in the cortex and the hippocampus (DeKosky and Scheff, 1990; Terry et al., 1991; Lassmann et al., 1993) possibly caused by soluble oligomers of the $\mathrm{AD}$ amyloid- $\beta$ protein (Shankar et al., 2007). One consequence of synapse loss is cognitive impairment caused by disruption of proper neuronal network function ( $\mathrm{Pa}$ lop et al., 2006). In addition, synapse and spine loss are likely to compromise synapse-to-nucleus communication and nuclear calcium signaling, thereby affecting CREB-ATF3 function as well as the expression of other target genes with roles in neuronal survival (Zhang et al., 2009). Thus, if calcium signal generation or propagation toward and into the nucleus is impaired, nuclear calcium-regulated genomic antiapoptotic programs may not be activated to the extent needed for health and survival. This condition, which could be described as a "nuclear calciopathy", causes a slowly progressing degeneration of neurons. Whether levels of Atf3 expression are reduced in $\mathrm{AD}$ remains to be investigated. However, consistent with the above-mentioned concept of the malfunctioning of calcium signaling in neurodegenerative diseases is the observation that in individuals with $\mathrm{AD}$ the levels of phosphorylation of CREB on its activator site serine 133 (an event induced by synaptic activity and calcium signaling) are reduced compared to an age-matched healthy control group (Yamamoto-Sasaki et al., 1999).

\section{Extrasynaptic NMDA receptors antagonize neuroprotection by nuclear calcium-CREB-ATF3 signaling}

Lack of synaptic activity may not be the only cause of impairment of nuclear calcium-CREB-ATF3 signaling. The function of this survival module could also be severely compromised by changes in the cell surface distribution of NMDA receptors, in particular a shift toward increased expression of extrasynaptic NMDA receptors that trigger a CREB shutoff and antagonize the survival-promoting activities of the synaptic NMDA receptors (Hardingham et al., 2002; Hardingham and Bading, 2010). This may be relevant for the etiology of Huntington's disease (HD), which leads to the death of medium spiny neurons in the striatum. Medium spiny neurons expressing mutant huntingtin (the sole cause of this disease) have increased surface expression of NMDA receptors at extrasynaptic sites, which increases their susceptibility to glutamate excitotoxicity (Fernandes et al., 2007; Fan et al., 2007; Okamoto et al., 2009; Milnerwood et al., 2010), a process initiated by death-promoting extrasynaptic NMDA receptors (Hardingham et al., 2002). Thus, in $\mathrm{HD}$ and possibly in other human neurodegenerative diseases, in particular $\mathrm{AD}$ in which NMDA receptors have been implicated in the etiology (Bossy-Wetzel et al., 2004), a shift in the balance from the survival-promoting synaptic NMDA receptors toward extrasynaptic NMDA receptors impairs prosurvival nuclear calcium signaling, ultimately leading to neuronal cell death.

\section{ATF3 as a new target for the therapy of neurodegenerative diseases}

The identification of the CREB target Atf 3 as a mediator of neuronal survival offers new potential therapies for neurodegenerative diseases. ATF3-based therapy (for example using viral vector-mediated gene delivery in vivo) provides significant advantages over attempts to manipulate survival at the level of CREB. Being a signal-regulated transcription factor, CREB function is controlled through posttranslational modifications rather than changes in expression level (Mayr and Montminy, 2001). A deliberate CREB activation would require the stimulation of signaling pathways impinging on CREB. Although possible, for example by using constitutively active kinases, such procedures will have highly pleiotropic effects with unwanted consequences and thus appear not suitable for a therapeutic strategy in humans. In contrast to CREB, ATF3 function is primarily controlled at the transcriptional level, allowing for an arrest of cell death using ATF3 supplementation. 


\section{Use of ATF3-VP16 for cell ablation}

The conversion of ATF3 to a transcriptional activator by means of fusion to VP16 converts ATF3 into a potent prodeath gene. Expression of VP16-ATF3 using cell type-specific promoters may prove a useful tool to efficiently ablate specific neuronal cell types in vivo.

\section{Conclusion}

Nuclear calcium, a signaling endpoint of synapse-to-nucleus communication, is a strong activator of cell survival and causes robust induction of the transcriptional repressor Atf3. The Atf 3 gene is a direct target of CREB and functions as a regulator of neuronal survival that links neuronal activity, synaptic NMDA receptor stimulation, and nuclear calcium-CREB signaling to a neuroprotective gene repression program.

\section{References}

Ahn S, Olive M, Aggarwal S, Krylov D, Ginty DD, Vinson C (1998) A dominant-negative inhibitor of CREB reveals that it is a general mediator of stimulus-dependent transcription of c-fos. Mol Cell Biol 18:967-977.

Anderson DJ (1999) Lineages and transcription factors in the specification of vertebrate primary sensory neurons. Curr Opin Neurobiol 9:517-524.

Anderson KA, Ribar TJ, Illario M, Means AR (1997) Defective survival and activation of thymocytes in transgenic mice expressing a catalytically inactive form of $\mathrm{Ca}^{2+} /$ calmodulin-dependent protein kinase IV. Mol Endocrinol 11:725-737.

Arnold FJ, Hofmann F, Bengtson CP, Wittmann M, Vanhoutte P, Bading H (2005) Microelectrode array recordings of cultured hippocampal networks reveal a simple model for transcription and protein synthesisdependent plasticity. J Physiol 564:3-19.

Bading H (2000) Transcription-dependent neuronal plasticity: The nuclear calcium hypothesis. Eur J Biochem 267:5280-5283.

Bading H, Greenberg ME (1991) Stimulation of protein tyrosine phosphorylation by NMDA receptor activation. Science 253:912-914.

Bading H, Ginty DD, Greenberg ME (1993) Regulation of gene expression in hippocampal neurons by distinct calcium signaling pathways. Science 260:181-186.

Bading H, Segal MM, Sucher NJ, Dudek H, Lipton SA, Greenberg ME (1995) $\mathrm{N}$-methyl-D-aspartate receptors are critical for mediating the effects of glutamate on intracellular calcium concentration and immediate early gene expression in cultured hippocampal neurons. Neuroscience 64:653-664.

Bengtson CP, Weislogel J-M, Freitag HE, Bading H (2010) Nuclear calcium sensors reveal that repetition of trains of synaptic stimuli boosts nuclear calcium signaling in CA1 pyramidal neurons. Biophys J 99:4066-4077.

Bossy-Wetzel E, Schwarzenbacher R, Lipton SA (2004) Molecular pathways to neurodegeneration. Nat Med 10:S2-S9.

Carlezon WA Jr, Thome J, Olson VG, Lane-Ladd SB, Brodkin ES, Hiroi N, Duman RS, Neve RL, Nestler EJ (1998) Regulation of cocaine reward by CREB. Science 282:2272-2275.

Carlezon WA Jr, Duman RS, Nestler EJ (2005) The many faces of CREB. Trends Neurosci 28:436-445.

Chawla S, Hardingham GE, Quinn DR, Bading H (1998) CBP: a signalregulated transcriptional coactivator controlled by nuclear calcium and CaM kinase IV. Science 281:1505-1509.

Chen BP, Liang G, Whelan J, Hai T (1994) ATF3 and ATF3 ZZip: transcriptional repression versus activation by alternatively spliced isoforms. J Biol Chem 269:15819-15826.

Curran T, Morgan JI (1995) Fos: an immediate-early transcription factor in neurons. J Neurobiol 26:403-412.

DeKosky ST, Scheff SW (1990) Synapse loss in frontal cortex biopsies in Alzheimer's disease: correlation with cognitive severity. Ann Neurol 27:457-464.

Dequéant ML, Pourquié O (2008) Segmental patterning of the vertebrate embryonic axis. Nat Rev Genet 9:370-382.

Fan MM, Fernandes HB, Zhang LY, Hayden MR, Raymond LA (2007) Altered NMDA receptor trafficking in a yeast artificial chromosome transgenic mouse model of Huntington's disease. J Neurosci 27:3768-3779.

Fernandes HB, Baimbridge KG, Church J, Hayden MR, Raymond LA (2007) (2007) Mitochondrial sensitivity and altered calcium handling underlie enhanced NMDA-induced apoptosis in YAC128 model of Huntington's disease. J Neurosci 27:13614-13623.

Fujita N, Jaye DL, Geigerman C, Akyildiz A, Mooney MR, Boss JM, Wade PA (2004) MTA3 and the Mi-2/NuRD complex regulate cell fate during B lymphocyte differentiation. Cell 119:75-86.

Giachino C, De Marchis S, Giampietro C, Parlato R, Perroteau I, Schütz G, Fasolo A, Peretto P (2005) cAMP response element-binding protein regulates differentiation and survival of newborn neurons in the olfactory bulb. J Neurosci 25:10105-10118.

Han J, Jiang Y, Li Z, Kravchenko VV, Ulevitch RJ (1997) Activation of the transcription factor MEF2C by the MAP kinase p38 in inflammation. Nature 386:296-299.

Hardingham GE, Bading H (2010) Synaptic versus extrasynaptic NMDA receptor signalling: implications for neurodegenerative disorders. Nat Rev Neurosci 11:682-696.

Hardingham GE, Chawla S, Johnson CM, Bading H (1997) Distinct functions of nuclear and cytoplasmic calcium in the control of gene expression. Nature 385:260-265.

Hardingham GE, Arnold FJ, Bading H (2001) Nuclear calcium signaling controls CREB-mediated gene expression triggered by synaptic activity. Nat Neurosci 4:261-267.

Hardingham GE, Fukunaga Y, Bading H (2002) Extrasynaptic NMDARs oppose synaptic NMDARs by triggering CREB shut-off and cell death pathways. Nat Neurosci 5:405-414.

Herrmann O, Baumann B, de Lorenzi R, Muhammad S, Zhang W, Kleesiek J, Malfertheiner M, Köhrmann M, Potrovita I, Maegele I, Beyer C, Burke JR, Hasan MT, Bujard H, Wirth T, Pasparakis M, Schwaninger M (2005) IKK mediates ischemia-induced neuronal death. Nat Med 11:1322-1329.

Klugmann M, Symes CW, Leichtlein CB, Klaussner BK, Dunning J, Fong D, Young D, During MJ (2005) AAV-mediated hippocampal expression of short and long Homer 1 proteins differentially affect cognition and seizure activity in adults rats. Mol Cell Neurosci 28:347-360.

Lassmann H, Fischer P, Jellinger K (1993) Synaptic pathology of Alzheimer's disease. Ann NY Acad Sci 695:59-64.

Lau D, Bading H (2009) Synaptic activity-mediated suppression of p53 and induction of nuclear calcium-regulated neuroprotective genes promote survival through inhibition of mitochondrial permeability transition. J Neurosci 29:4420-4429.

Lee B, Butcher GQ, Hoyt KR, Impey S, Obrietan K (2005) Activitydependent neuroprotection and cAMP response element-binding protein (CREB): kinase coupling, stimulus intensity, and temporal regulation of CREB phosphorylation at serine 133. J Neurosci 25:1137-1148.

Lemrow SM, Anderson KA, Joseph JD, Ribar TJ, Noeldner PK, Means AR (2004) Catalytic activity is required for calcium/calmodulin-dependent protein kinase IV to enter the nucleus. J Biol Chem 279:11664-11671.

Liang G, Wolfgang CD, Chen BP, Chen TH, Hai T (1996) ATF3 gene: genomic organization, promoter, and regulation. J Biol Chem 271:1695-1701.

Lonze BE, Ginty DD (2002) Function and regulation of CREB family transcription factors in the nervous system. Neuron 35:605-623.

Mantamadiotis T, Lemberger T, Bleckmann SC, Kern H, Kretz O, Martin Villalba A, Tronche F, Kellendonk C, Gau D, Kapfhammer J, Otto C, Schmid W, Schütz G (2002) Disruption of CREB function in brain leads to neurodegeneration. Nat Genet 31:47-54.

Mao Z, Bonni A, Xia F, Nadal-Vicens M, Greenberg ME (1999) Neuronal activity-dependent cell survival mediated by transcription factor MEF2. Science 286:785-790.

Martinou JC, Dubois-Dauphin M, Staple JK, Rodriguez I, Frankowski H, Missotten M, Albertini P, Talabot D, Catsicas S, Pietra C, Huarte J (1994) Overexpression of BCL-2 in transgenic mice protects neurons from naturally occurring cell death and experimental ischemia. Neuron 13:10171030.

Mayr B, Montminy M (2001) Transcriptional regulation by the phosphorylation-dependent factor CREB. Nat Rev Mol Cell Biol 2:599-609.

McKinsey TA, Zhang CL, Olson EN (2002) MEF2: a calcium-dependent regulator of cell division, differentiation and death. Trends Biochem Sci 27:40-47.

Milnerwood AJ, Gladding CM, Pouladi MA, Kaufman AM, Hines RM, Boyd JD, Ko RW, Vasuta OC, Graham RK, Hayden MR, Murphy TH, Raymond LA (2010) Early increase in extrasynaptic NMDA receptor signaling and expression contributes to phenotype onset in Huntington's disease mice. Neuron 65:178-190. 
Molkentin JD, Black BL, Martin JF, Olson EN (1996) Mutational analysis of the DNA binding, dimerization, and transcriptional activation domains of MEF2C. Mol Cell Biol 16:2627-2636.

Murikinati S, Jüttler E, Keinert T, Ridder DA, Muhammad S, Waibler Z, Ledent C, Zimmer A, Kalinke U, Schwaninger M (2010) Activation of cannabinoid 2 receptors protects against cerebral ischemia by inhibiting neutrophil recruitment. FASEB J 24:788-798.

Okamoto S, Pouladi MA, Talantova M, Yao D, Xia P, Ehrnhoefer DE, Zaidi R, Clemente A, Kaul M, Graham RK, Zhang D, Vincent Chen HS, Tong G, Hayden MR, Lipton SA (2009) Balance between synaptic versus extrasynaptic NMDA receptor activity influences inclusions and neurotoxicity of mutant huntingtin. Nat Med 15:1407-1413.

Palop JJ, Chin J, Mucke L (2006) A network dysfunction perspective on neurodegenerative diseases. Nature 443:768-773.

Papadia S, Stevenson P, Hardingham NR, Bading H, Hardingham GE (2005) Nuclear calcium and CREB family mediate a late phase of activitydependent neuroprotection. J Neurosci 25:4279-4287.

Pearson JC, Lemons D, McGinnis W (2005) Modulating Hox gene functions during animal body patterning. Nat Rev Genet 6:893-904.

Peel AD, Chipman AD, Akam M (2005) Arthropod segmentation: beyond the Drosophila paradigm. Nat Rev Genet 6:905-916.

Riccio A, Ahn S, Davenport CM, Blendy JA, Ginty DD (1999) Mediation by a CREB family transcription factor of NGF-dependent survival of sympathetic neurons. Science 286:2358-2361.

Schmued LC, Stowers CC, Scallet AC, Xu L (2005) Fluoro-Jade C results in ultra high resolution and contrast labeling of degenerating neurons. Brain Res 1035:24-31.

Shankar GM, Bloodgood BL, Townsend M, Walsh DM, Selkoe DJ, Sabatini BL (2007) Natural oligomers of the Alzheimer amyloid-beta protein induce reversible synapse loss by modulating an NMDA-type glutamate receptor-dependent signaling pathway. J Neurosci 27:2866-2875.

Silva AJ, Kogan JH, Frankland PW, Kida S (1998) CREB and memory. Annu Rev Neurosci 21:127-148.

Smith R, Brundin P, Li JY (2005) Synaptic dysfunction in Huntington's disease: a new perspective. Cell Mol Life Sci 62:1901-1912.
Sun P, Enslen H, Myung PS, Maurer RA (1994) Differential activation of CREB by $\mathrm{Ca}^{2+} /$ calmodulin-dependent protein kinases type II and type IV involves phosphorylation of a site that negatively regulates activity. Genes Dev 8:2527-2539.

Terry RD, Masliah E, Salmon DP, Butters N, DeTeresa R, Hill R, Hansen LA, Katzman R (1991) Physical basis of cognitive alterations in Alzheimer's disease: synapse loss is the major correlate of cognitive impairment. Ann Neurol 30:572-580.

Wang J, Campos B, Jamieson GA Jr, Kaetzel MA, Dedman JR (1995) Functional elimination of calmodulin within the nucleus by targeted expression of an inhibitor peptide. J Biol Chem 270:30245-30248.

Yamamoto-Sasaki M, Ozawa H, Saito T, Rösler M, Riederer P (1999) Impaired phosphorylation of cyclic AMP response element binding protein in the hippocampus of dementia of the Alzheimer type. Brain Res 824:300-303.

Youn HD, Chatila TA, Liu JO (2000) Integration of calcineurin and MEF2 signals by the coactivator p300 during T-cell apoptosis. EMBO J 19:4323-4331.

Zhang SJ, Steijaert MN, Lau D, Schütz G, Delucinge-Vivier C, Descombes P, Bading H (2007) Decoding NMDA receptor signaling: identification of genomic programs specifying neuronal survival and death. Neuron 53:549-562.

Zhang SJ, Zou M, Lu L, Lau D, Ditzel DA, Delucinge-Vivier C, Aso Y, Descombes P, Bading H (2009) Nuclear calcium signaling controls expression of a large gene pool: identification of a gene program for acquired neuroprotection induced by synaptic activity. PLoS Genet. 5:e1000604.

Zhang W, Potrovita I, Tarabin V, Herrmann O, Beer V, Weih F, Schneider A, Schwaninger M (2005) Neuronal activation of NF-kappaB contributes to cell death in cerebral ischemia. J Cereb Blood Flow Metab 25:30-40.

Zhu DY, Lau L, Liu SH, Wei JS, Lu YM (2004) Activation of cAMPresponse-element-binding protein (CREB) after focal cerebral ischemia stimulates neurogenesis in the adult dentate gyrus. Proc Natl Acad Sci U S A 101:9453-9457. 